\title{
Multicomponent Polymerization of Alkynes, Isocyanides and Isocyanates toward Heterocyclic Polymers
}

Xiaoheng Wang, ${ }^{\dagger}$ Baixue Li, ${ }^{\dagger}$ Jianwen Peng, ${ }^{\dagger}$ Bingnan Wang, ${ }^{\dagger}$ Anjun Qin ${ }^{* \dagger}$ and Ben Zhong Tang ${ }^{\dagger,}$

${ }^{\dagger}$ State Key Laboratory of Luminescent Materials and Devices, Guangdong Provincial Key Laboratory of Luminescence from Molecular Aggregates, AIE Institute, Center for Aggregation-Induced Emission, South China University of Technology, Guangzhou 510640, China. E-mail: msqinaj@scut.edu.cn.

* Shenzhen Institute of Aggregate Science and Technology, School of Science and Engineering, The Chinese University of Hong Kong, Shenzhen 518172, China. 


\section{Table of Contents}

Monomer synthesis.

Model reaction.

Scheme S1. Synthesis of 3a.

Scheme S2. Synthesis of $\mathbf{3 b}$.

Scheme S3. The proposed mechanism of MCP.

Scheme S4. Synthesis of model compound 4.

Figure S1. HRMS spectra of model compound 4.

Figure S2. GPC traces of P1a2a3a-P1b2b3b.

Figure S3. FT-IR spectra of 1a (A), 2a (B), 3a (C) and P1a2a3a (D).

Figure S4. FT-IR spectra of 1a (A), 2a (B), 3b (C) and P1a2a3b (D).

Figure S5. FT-IR spectra of 1a (A), 2b (B), 3b (C) and P1a2b3b (D).

Figure S6. FT-IR spectra of $\mathbf{1 b}(\mathrm{A}), \mathbf{2 a}(\mathrm{B}), \mathbf{3 a}(\mathrm{C})$ and P1b2a3a (D).

Figure S7. FT-IR spectra of $\mathbf{1 b}(\mathrm{A}), \mathbf{2 b}(\mathrm{B}), \mathbf{3 a}(\mathrm{C})$ and P1b2b3a (D).

Figure S8. FT-IR spectra of $\mathbf{1 b}(\mathrm{A}), \mathbf{2 a}(\mathrm{B}), \mathbf{3 b}(\mathrm{C})$ and P1b2a3b (D).

Figure S9. FT-IR spectra of $\mathbf{1 b}(\mathrm{A}), \mathbf{2 b}(\mathrm{B}), \mathbf{3 b}(\mathrm{C})$ and P1b2b3b (D).

Figure S10. FT-IR spectra of 1a (A), 2a (B), 3c (C) and P1a2a3c (D).

Figure S11. FT-IR spectra of 1a (A), 2b (B), 3c (C) and P1a2b3c (D).

Figure S12. ${ }^{1} \mathrm{H}$ NMR spectra of $\mathbf{1 a}(\mathrm{A}), \mathbf{2 a}(\mathrm{B}), \mathbf{3 a}(\mathrm{C})$ and P1a2a3a (D) in $\mathrm{CDCl}_{3}$. The solvent peaks are marked with asterisks.

Figure S13. ${ }^{1} \mathrm{H}$ NMR spectra of $\mathbf{1 a}(\mathrm{A}), \mathbf{2 a}(\mathrm{B}), \mathbf{3 b}(\mathrm{C})$ and $\mathrm{P} \mathbf{1 a 2 a 3 b}(\mathrm{D})$ in $\mathrm{CDCl}_{3}$. The solvent peaks are marked with asterisks. 
Figure S14. ${ }^{1} \mathrm{H}$ NMR spectra of $1 \mathbf{a}(\mathrm{A}), \mathbf{2 a}(\mathrm{B}), \mathbf{3 c}(\mathrm{C})$ and P1a2a3c (D) in $\mathrm{CDCl}_{3}$. The solvent peaks are marked with asterisks.

Figure S15. ${ }^{1} \mathrm{H}$ NMR spectra of $1 \mathbf{a}(\mathrm{A}), \mathbf{2 b}(\mathrm{B}), \mathbf{3 b}(\mathrm{C})$ and $\mathrm{P} 1 \mathbf{a} 2 \mathbf{b 3 b}(\mathrm{D})$ in $\mathrm{CDCl}_{3}$. The solvent peaks are marked with asterisks.

Figure S16. ${ }^{1} \mathrm{H}$ NMR spectra of $1 \mathbf{a}(\mathrm{A}), \mathbf{2 b}(\mathrm{B}), \mathbf{3 c}(\mathrm{C})$ and $\mathrm{P} 1 \mathbf{a 2 b 3 c}(\mathrm{D})$ in $\mathrm{CDCl}_{3}$. The solvent peaks are marked with asterisks.

Figure S17. ${ }^{1} \mathrm{H}$ NMR spectra of $\mathbf{1 b}(\mathrm{A}), \mathbf{2 a}(\mathrm{B}), \mathbf{3 a}(\mathrm{C})$ and P1b2a3a (D) in $\mathrm{CDCl}_{3}$. The solvent peaks are marked with asterisks.

Figure S18. ${ }^{1} \mathrm{H}$ NMR spectra of $\mathbf{1 b}(\mathrm{A}), \mathbf{2 a}(\mathrm{B}), \mathbf{3 b}(\mathrm{C})$ and $\mathrm{P} \mathbf{1 b 2 a 3 b}(\mathrm{D})$ in $\mathrm{CDCl}_{3}$. The solvent peaks are marked with asterisks.

Figure S19. ${ }^{1} \mathrm{H}$ NMR spectra of $\mathbf{1 b}(\mathrm{A}), \mathbf{2 b}(\mathrm{B}), \mathbf{3 a}(\mathrm{C})$ and P1b2a3a (D) in $\mathrm{CDCl}_{3}$. The solvent peaks are marked with asterisks.

Figure S20. ${ }^{1} \mathrm{H}$ NMR spectra of $\mathbf{1 b}(\mathrm{A}), \mathbf{2 b}(\mathrm{B}), \mathbf{3 b}(\mathrm{C})$ and $\mathrm{P} \mathbf{1 b 2 b 3 b}(\mathrm{D})$ in $\mathrm{CDCl}_{3}$. The solvent peaks are marked with asterisks.

Figure S21. ${ }^{13} \mathrm{C}$ NMR spectra of $1 \mathbf{a}(\mathrm{A}), \mathbf{2 a}(\mathrm{B}), \mathbf{3 a}(\mathrm{C})$ and P1a2a3a (D) in $\mathrm{CDCl}_{3}$. The solvent peaks are marked with asterisks.

Figure S22. ${ }^{13} \mathrm{C}$ NMR spectra of $1 \mathbf{a}(\mathrm{A}), \mathbf{2 a}(\mathrm{B}), \mathbf{3 b}(\mathrm{C})$ and $\mathrm{P} 1 \mathbf{a} 2 \mathbf{a} 3 \mathbf{b}(\mathrm{D})$ in $\mathrm{CDCl}_{3}$. The solvent peaks are marked with asterisks.

Figure S23. ${ }^{13} \mathrm{C}$ NMR spectra of $1 \mathbf{a}(\mathrm{A}), \mathbf{2 a}(\mathrm{B}), \mathbf{3 c}(\mathrm{C})$ and P1a2a3c (D) in $\mathrm{CDCl}_{3}$. The solvent peaks are marked with asterisks.

Figure S24. ${ }^{13} \mathrm{C}$ NMR spectra of $1 \mathbf{a}(\mathrm{A}), \mathbf{2 b}(\mathrm{B}), \mathbf{3 b}(\mathrm{C})$ and $\mathrm{P} 1 \mathbf{a} 2 \mathbf{b 3 b}(\mathrm{D})$ in $\mathrm{CDCl}_{3}$. The solvent peaks are marked with asterisks. 
Figure S25. ${ }^{13} \mathrm{C}$ NMR spectra of $\mathbf{1 a}(\mathrm{A}), \mathbf{2 b}(\mathrm{B}), \mathbf{3 c}(\mathrm{C})$ and $\mathrm{P} \mathbf{1 a 2 b 3 c}(\mathrm{D})$ in $\mathrm{CDCl}_{3}$. The solvent peaks are marked with asterisks.

Figure S26. ${ }^{13} \mathrm{C}$ NMR spectra of $\mathbf{1 b}(\mathrm{A}), \mathbf{2 a}(\mathrm{B}), \mathbf{3 a}(\mathrm{C})$ and P1b2a3a (D) in $\mathrm{CDCl}_{3}$. The solvent peaks are marked with asterisks.

Figure S27. ${ }^{13} \mathrm{C}$ NMR spectra of $\mathbf{1 b}(\mathrm{A}), \mathbf{2 a}(\mathrm{B}), \mathbf{3 b}(\mathrm{C})$ and $\mathrm{P} \mathbf{1 b 2 a 3 b}(\mathrm{D})$ in $\mathrm{CDCl}_{3}$. The solvent peaks are marked with asterisks.

S28

Figure S28. ${ }^{13} \mathrm{C}$ NMR spectra of $\mathbf{1 b}(\mathrm{A}), \mathbf{2 b}(\mathrm{B}), \mathbf{3 a}(\mathrm{C})$ and $\mathrm{P} 1 \mathbf{b 2 b 3 a}(\mathrm{D})$ in $\mathrm{CDCl}_{3}$. The solvent peaks are marked with asterisks.

Figure S29. ${ }^{13} \mathrm{C}$ NMR spectra of $\mathbf{1 b}(\mathrm{A}), \mathbf{2 b}(\mathrm{B}), \mathbf{3 b}(\mathrm{C})$ and $\mathrm{P} \mathbf{1 b 2 b 3 b}(\mathrm{D})$ in $\mathrm{CDCl}_{3}$. The solvent peaks are marked with asterisks.

S30

Figure S30. (A) Differential scanning calorimetry (DSC) analysis of P1a2a3a-P1a2b3b. (B) DSC analysis of P1a2a3b-P1a2b3c.

Table S1. The effect of acidic conditions on P1a2b3a.

Figure S31. ${ }^{1} \mathrm{H}$ NMR spectra of P1a2b3a before (A) and after $(\mathrm{B})$ stirring in $\mathrm{THF} / \mathrm{HCl}$ with $\mathrm{pH}=3$. The solvent peaks are marked with asterisks.

Figure S32. ${ }^{13} \mathrm{C}$ NMR spectra of P1a2b3a before $(\mathrm{A})$ and after $(\mathrm{B})$ stirring in $\mathrm{THF} / \mathrm{HCl}$ with $\mathrm{pH}=3$. The solvent peaks are marked with asterisks. S32

Figure S33. ${ }^{1} \mathrm{H}$ NMR spectra of model compound 4 before (A) and after (B) stirring in $\mathrm{THF} / \mathrm{HCl}$ with $\mathrm{pH}=3$. The solvent peaks are marked with asterisks.

Figure S34. ${ }^{13} \mathrm{C}$ NMR spectra of model compound 4 before (A) and after (B) stirring in $\mathrm{THF} / \mathrm{HCl}$ with $\mathrm{pH}=3$. The solvent peaks are marked with asterisks.

Table S2. Refractive indices $\left(n_{\mathrm{D}}\right)$, Abbé numbers $\left(v_{\mathrm{D}}\right)$, modified Abbé numbers $\left(v_{\mathrm{D}}^{\prime}\right)$, optical 
dispersions $\left(D\right.$ and $\left.D^{\prime}\right)$ and thickness of thin films of polymers P1a2a3a-P1b2b3b. S34

$\begin{array}{ll}\text { Table S3. Refractive indices }\left(n_{\mathrm{D}}\right) \text { of commercial polymers. } & \text { S34 }\end{array}$

$\begin{array}{ll}\text { References } & \text { S35 }\end{array}$ 
Monomer synthesis. Isocyanides monomers of bis(3-ethyl-4-isocyano-5-methylphenyl)methane (3a) and 1,4-bis(isocyanomethyl)benzene (3b) were synthesized according to the literature. ${ }^{1}$ The detailed synthetic routes are shown in Scheme S1 and S2.

Bis(3-ethyl-4-isocyano-5-methylphenyl)methane (3a): ${ }^{1} \mathrm{H} \mathrm{NMR}\left(500 \mathrm{MHz}, \mathrm{CDCl}_{3}\right) \delta$ (TMS, ppm): 6.89, 6.88, 3.86, 2.75, 2.74, 2.38, 1.26, 1.24, 1.22. $\left.{ }^{13} \mathrm{C} \mathrm{NMR} \mathrm{(125} \mathrm{MHz,} \mathrm{CDCl}_{3}\right) \delta(\mathrm{TMS}, \mathrm{ppm}): 167.78$, $141.36,141.07,135.49,128.38,126.87,41.47,25.94,19.14,14.08$.

1,4-Bis(isocyanomethyl)benzene (3b): ${ }^{1} \mathrm{H} \mathrm{NMR}\left(500 \mathrm{MHz}, \mathrm{CDCl}_{3}\right) \delta$ (TMS, ppm): 7.32, 7.30, 7.18, 7.16, 4.01, 1.58. ${ }^{13} \mathrm{C}$ NMR (125 MHz, $\left.\mathrm{CDCl}_{3}\right) \delta$ (TMS, ppm): 164.23, 141.63, 129.97, 126.82, 41.25. Synthesis of Model compound. The model compound 4 was prepared according to the published procedures. ${ }^{2}$ The detailed synthetic routes are shown in Scheme S4. A yellow powder was obtained in $78 \%$ yield. IR (KBr disk), $v\left(\mathrm{~cm}^{-1}\right): 3286,2978,2924,2875,1613,1474,1436,1377,1333,1272,1136$, 1098, 1062, 1008, 923, 888, 859, 813, 726, 674, 606, 557. ${ }^{1} \mathrm{H}$ NMR (500 MHz, $\left.\mathrm{CDCl}_{3}\right) \delta(\mathrm{TMS}, \mathrm{ppm})$ :

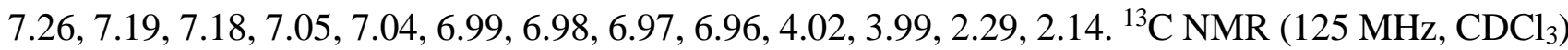
$\delta$ (TMS, ppm): 160.86, 160.28, 148.08, 146.30, 143.62, 141.26, 140.70, 138.28, 133.07, 129.69, $127.84,127.41,126.48,124.67,53.60,21.32,18.38$.

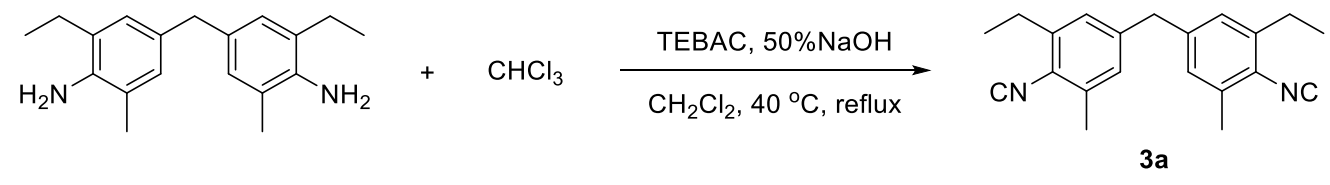

Scheme S1. Synthesis of 3a.

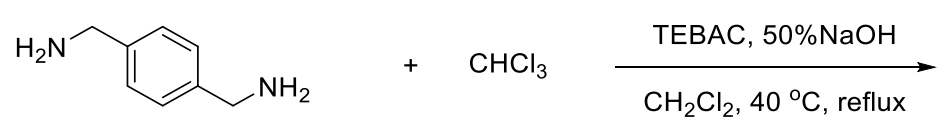<smiles>[N-]Cc1ccc(CN=[N+]=[N-])cc1</smiles>

$3 \mathbf{b}$

Scheme S2. Synthesis of $\mathbf{3 b}$. 


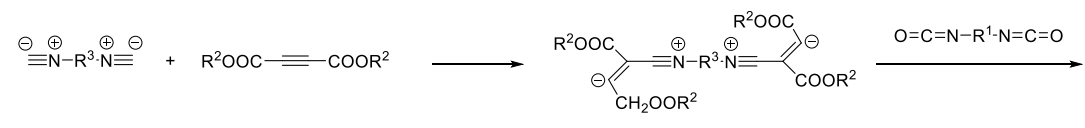
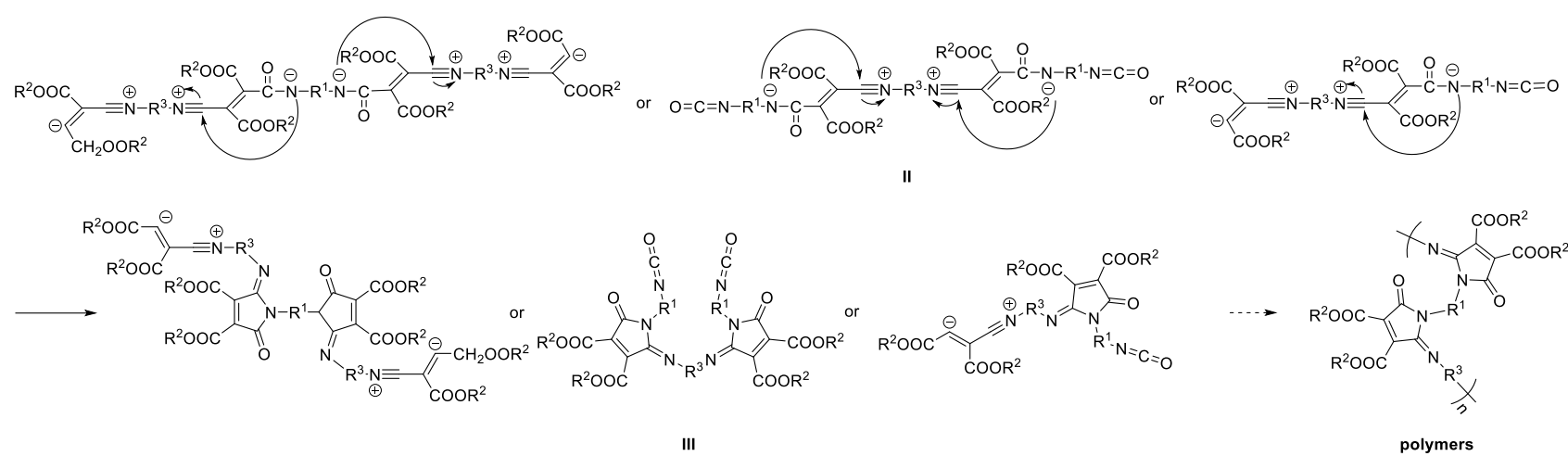

Scheme S3. The proposed mechanism of MCP.

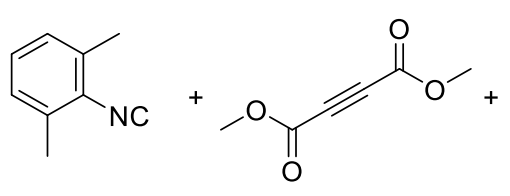<smiles>Cc1ccc(N=C=O)cc1</smiles>

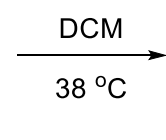<smiles>[CH2]c1cccc(C)c1N=C1C(C(=O)OC)=C(C(=O)OC)C(=O)N1c1ccc(C)cc1</smiles>

Scheme S4. Synthesis of model compound 4.

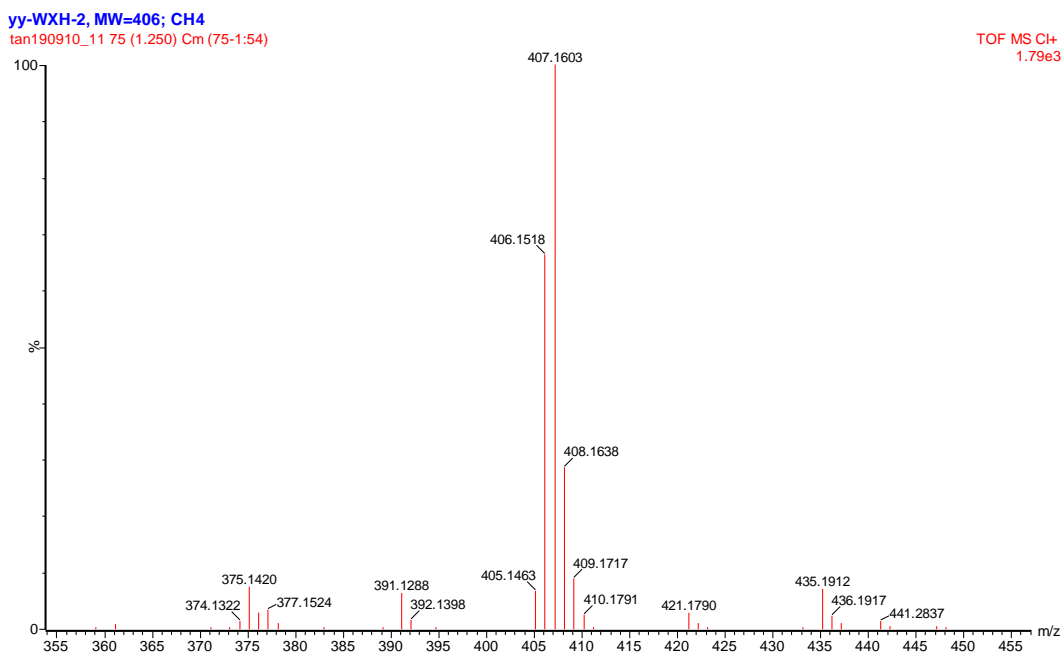

Figure S1. HRMS spectra of model compound 4. 


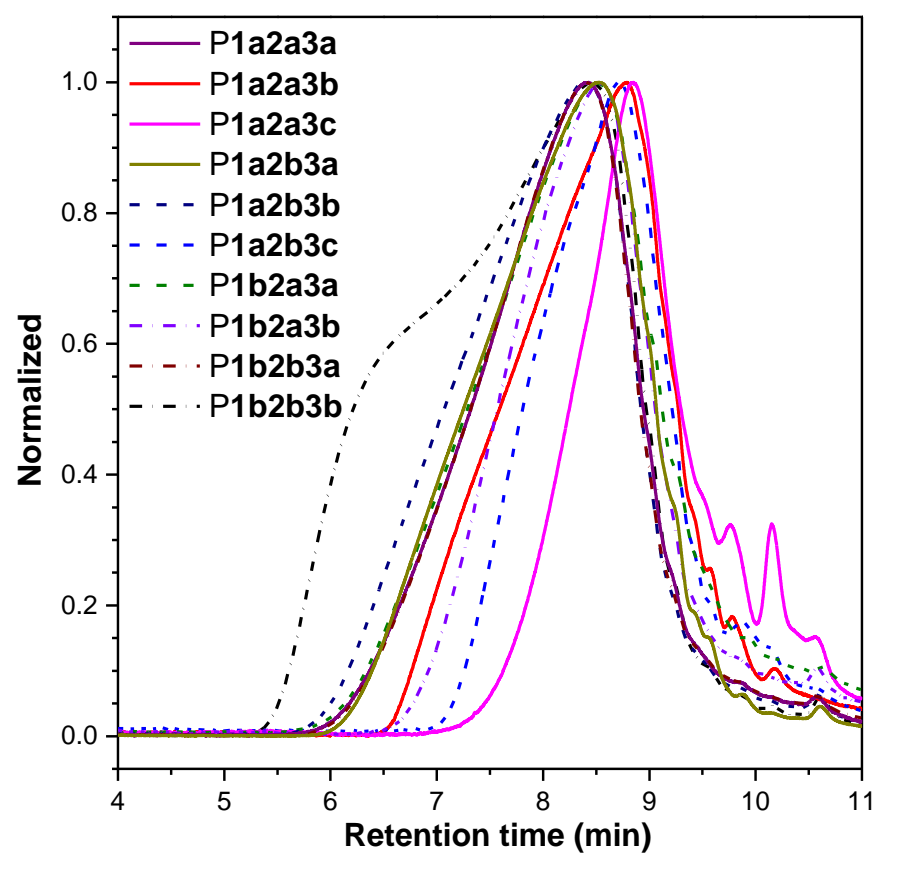

Figure S2. GPC traces of P1a2a3a-P1b2b3b.
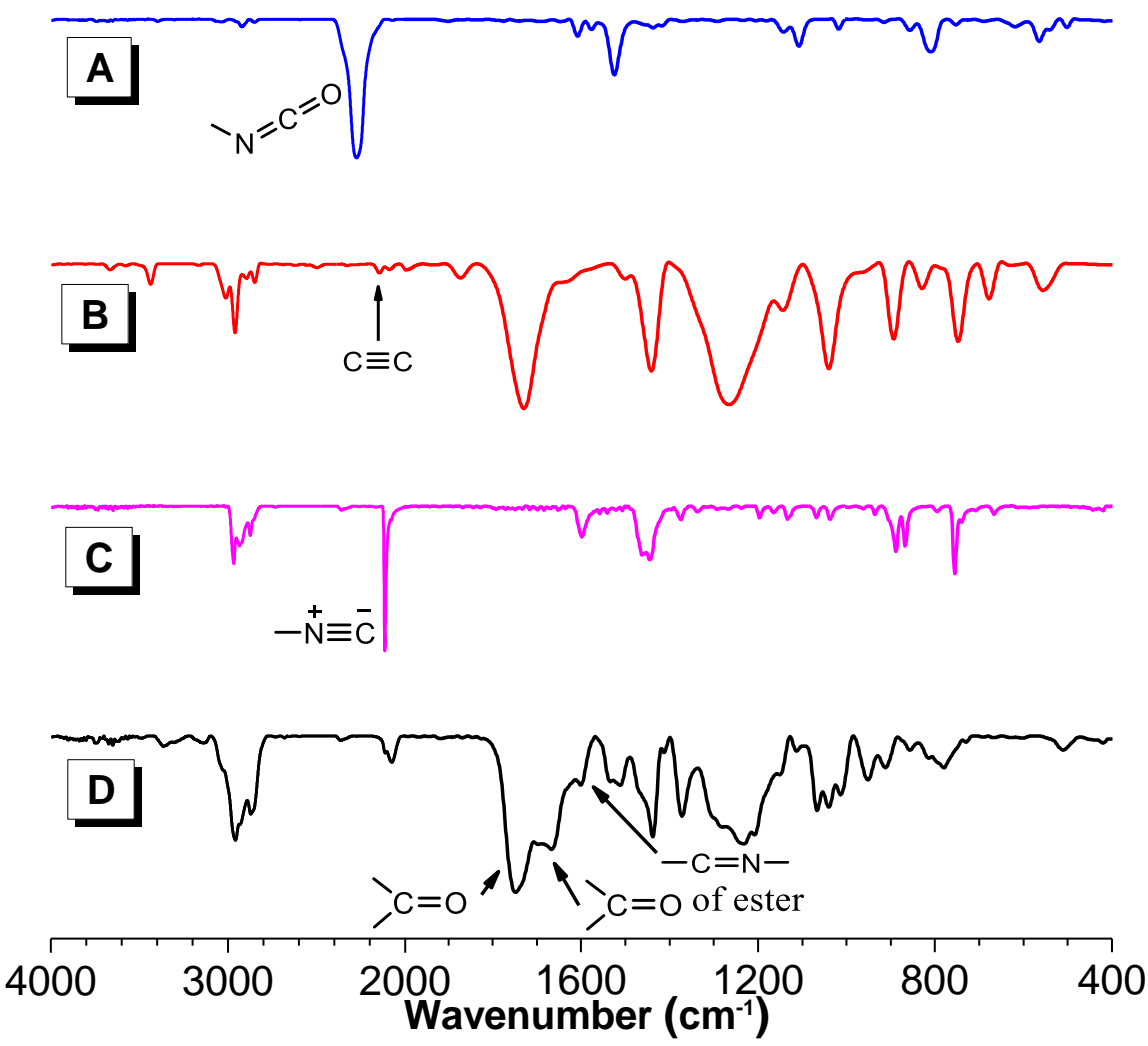

Figure S3. FT-IR spectra of 1a (A), 2a (B), 3a (C) and P1a2a3a (D). 

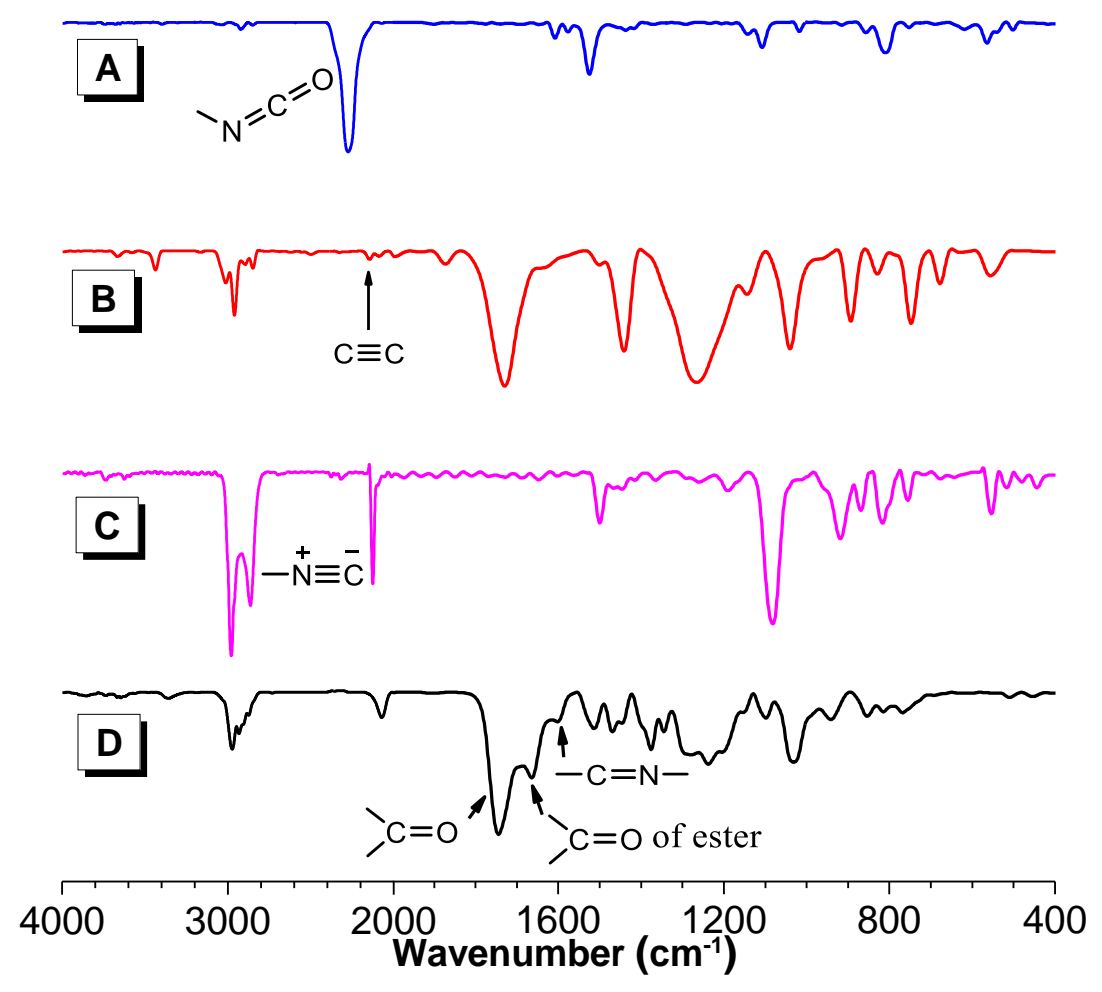

Figure S4. FT-IR spectra of 1a (A), 2a (B), 3b (C) and P1a2a3b (D).
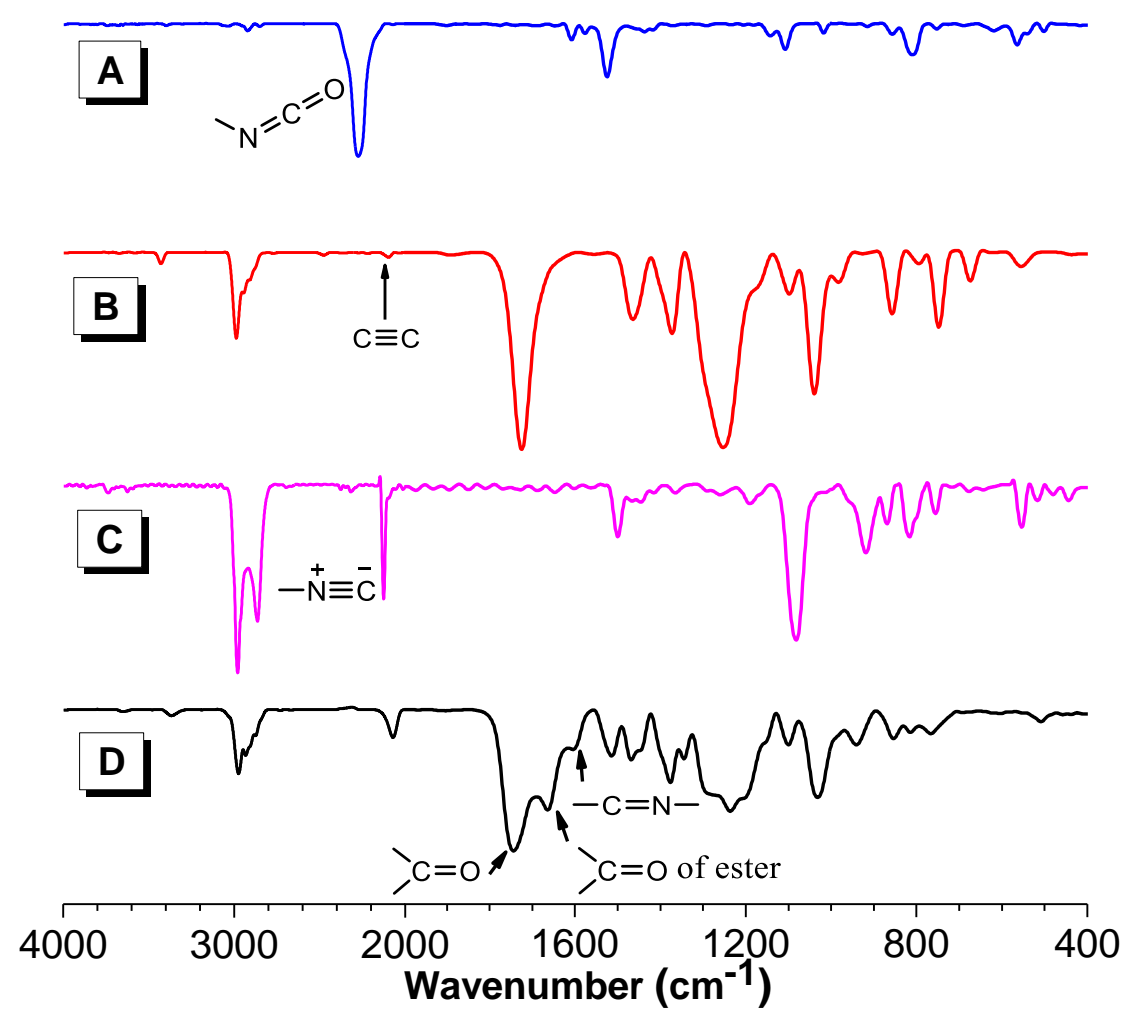

Figure S5. FT-IR spectra of $1 \mathbf{a}(\mathrm{A}), \mathbf{2 b}(\mathrm{B}), \mathbf{3 b}(\mathrm{C})$ and P1a2b3b (D). 


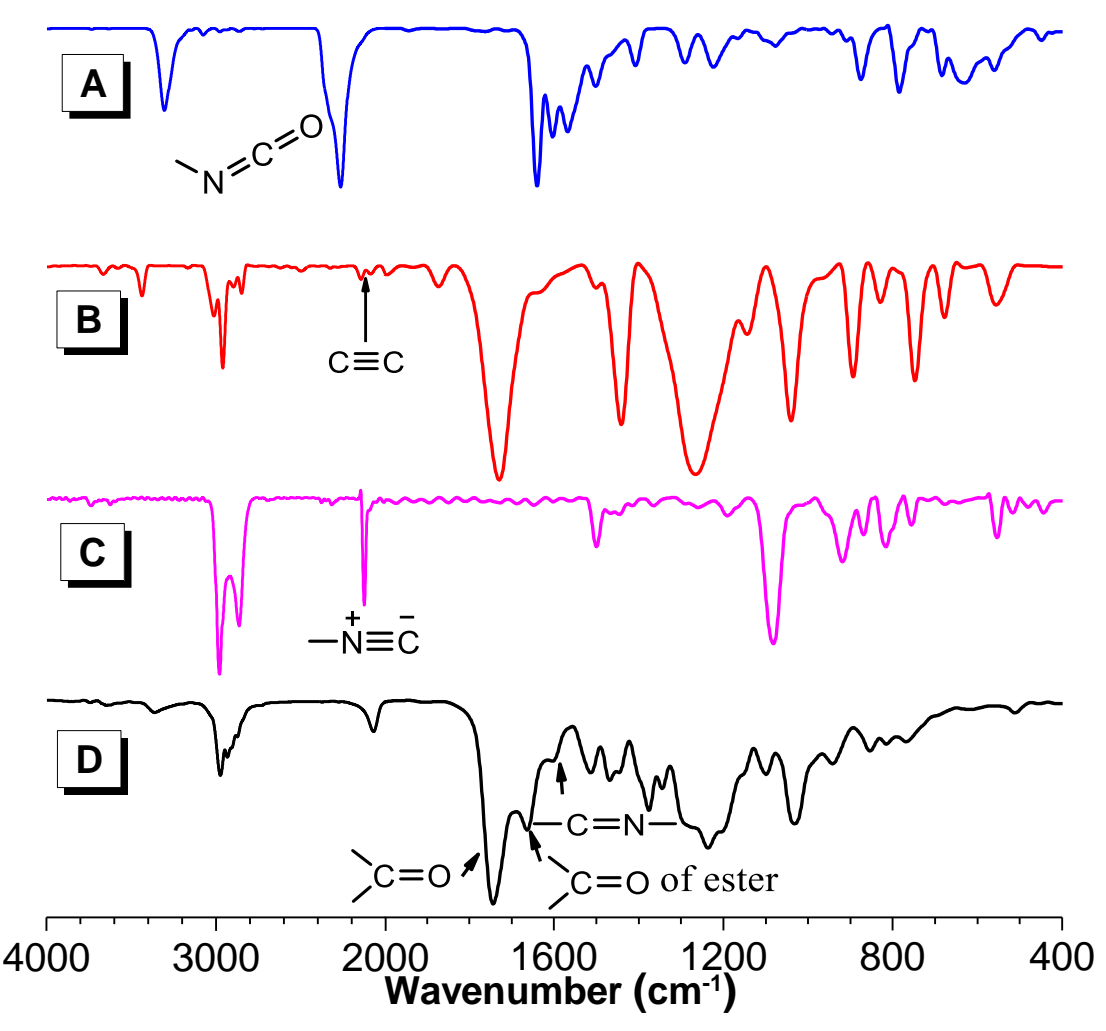

Figure S6. FT-IR spectra of $\mathbf{1 b}(\mathrm{A}), \mathbf{2 a}(\mathrm{B}), \mathbf{3 a}(\mathrm{C})$ and P1b2a3a (D).

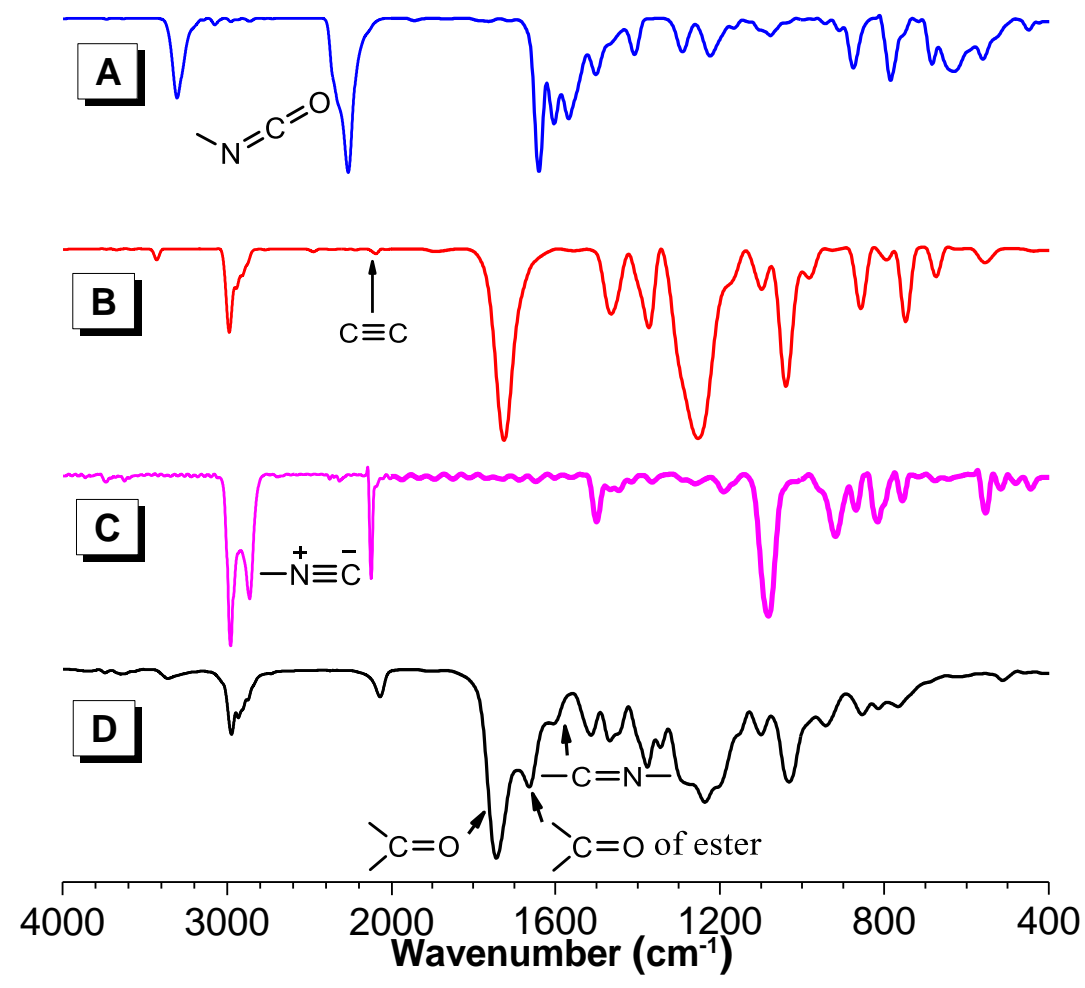

Figure S7. FT-IR spectra of $\mathbf{1 b}(\mathrm{A}), \mathbf{2 b}(\mathrm{B}), \mathbf{3 a}(\mathrm{C})$ and P1b2b3a (D). 

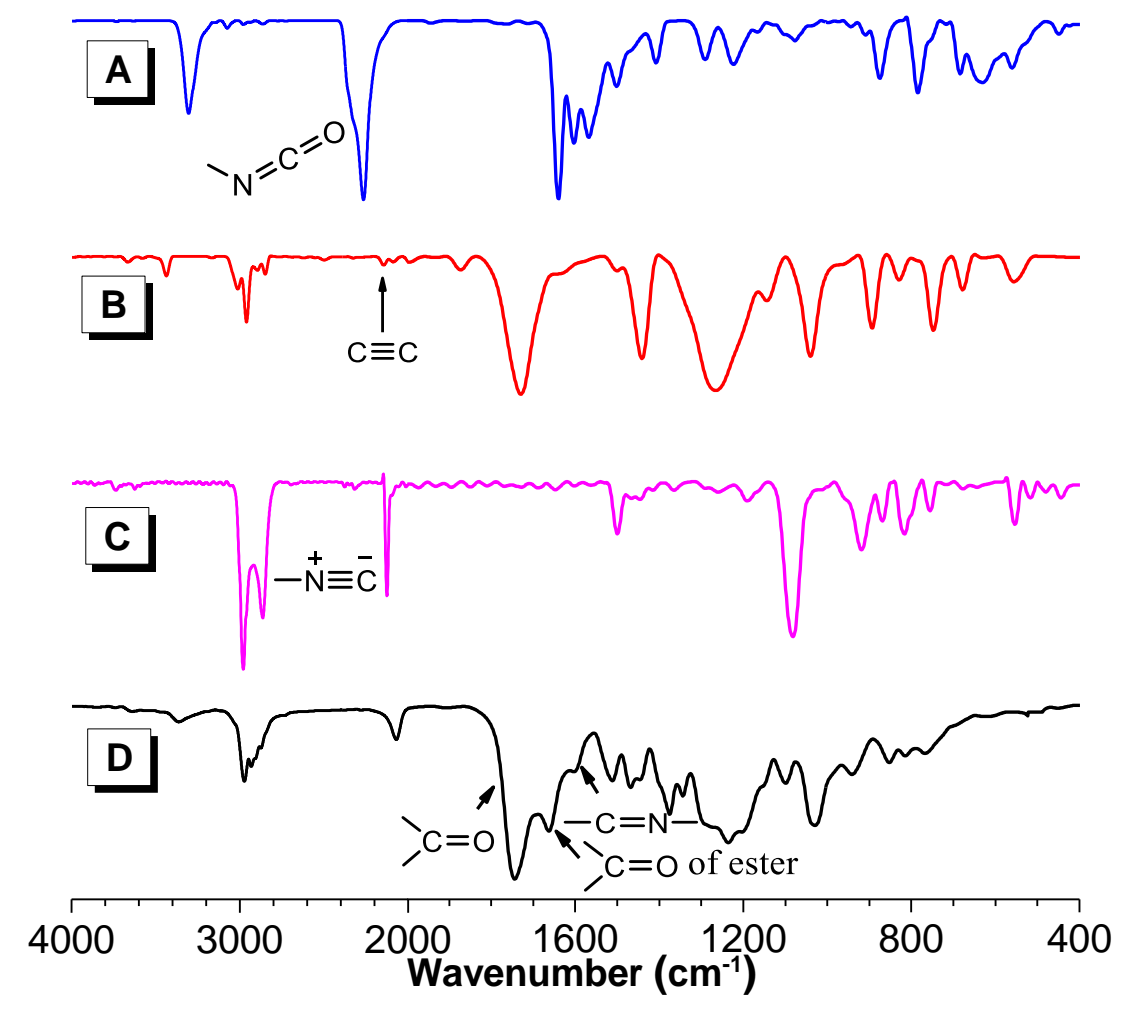

Figure S8. FT-IR spectra of 1b (A), 2a (B), 3b (C) and P1b2a3b (D).

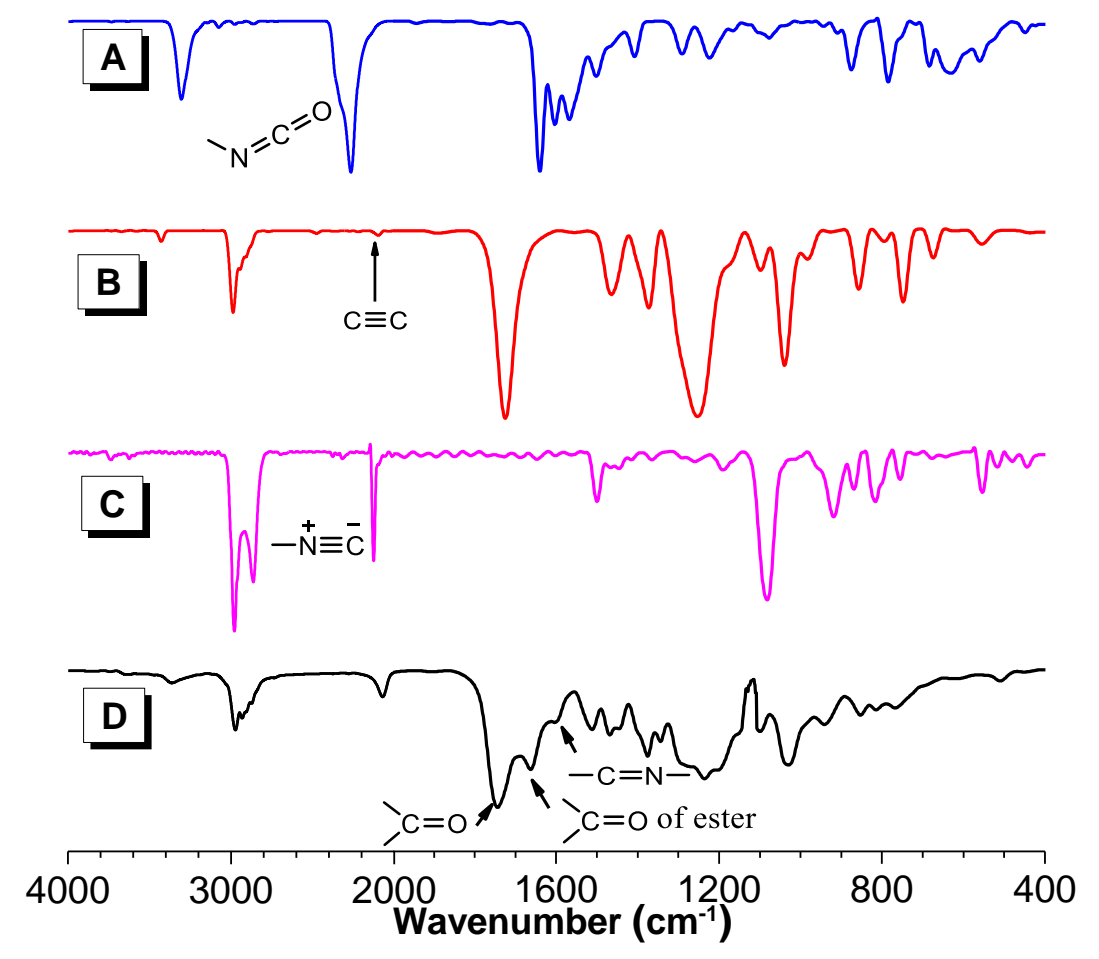

Figure S9. FT-IR spectra of $\mathbf{1 b}(\mathrm{A}), \mathbf{2 b}(\mathrm{B}), \mathbf{3 b}(\mathrm{C})$ and P1b2b3b (D). 

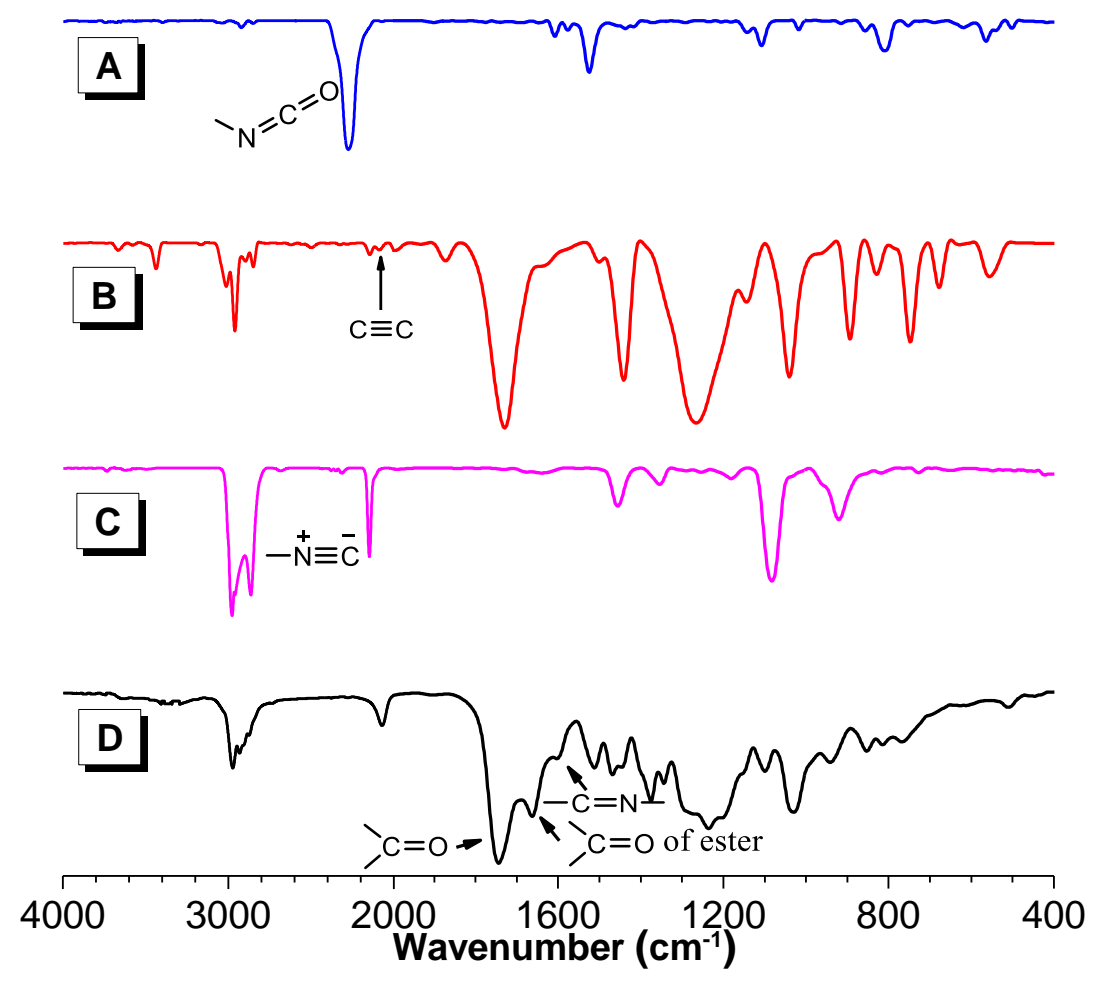

Figure S10. FT-IR spectra of 1a (A), 2a (B), 3c (C) and P1a2a3c (D).
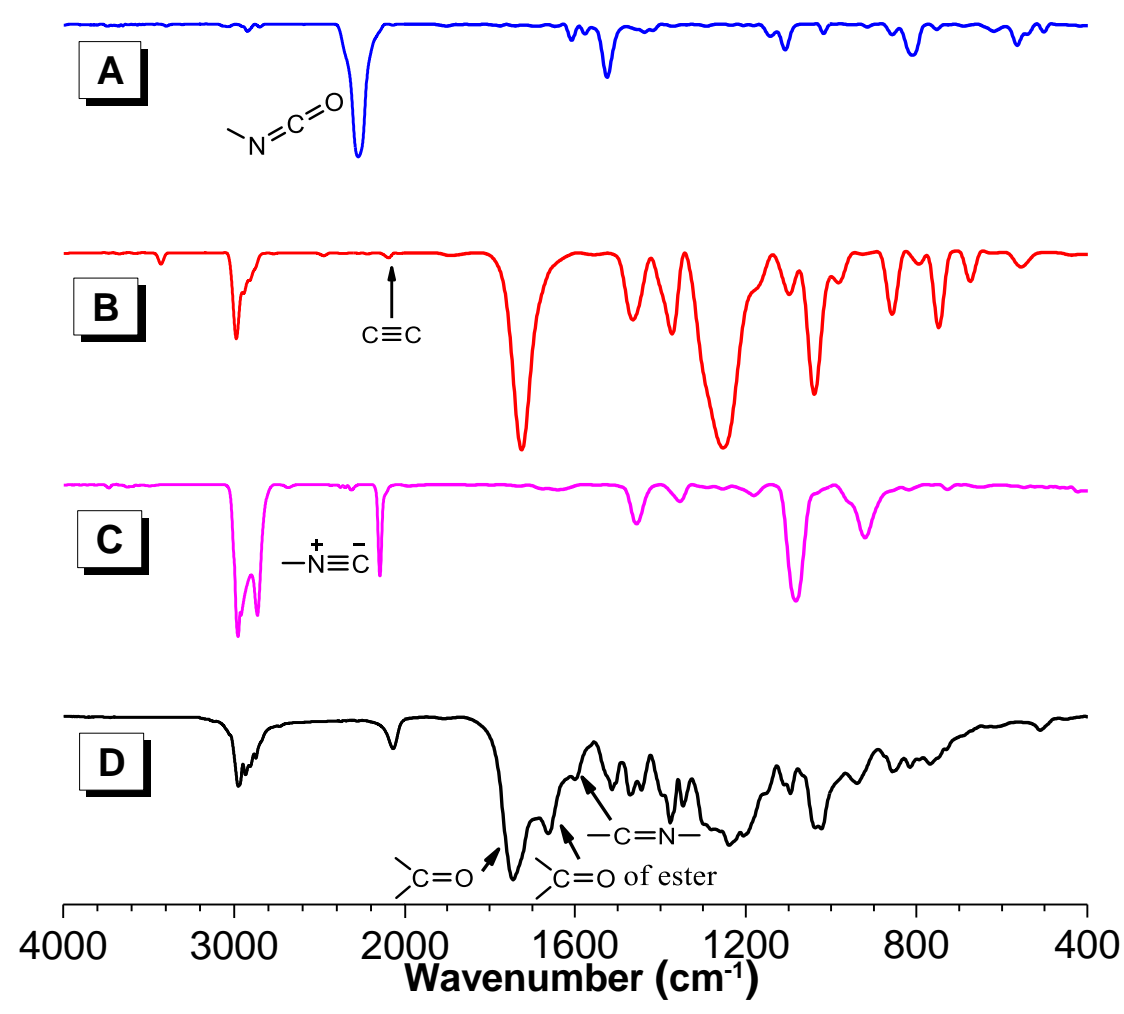

Figure S11. FT-IR spectra of 1a (A), 2b (B), 3c (C) and P1a2b3c (D). 

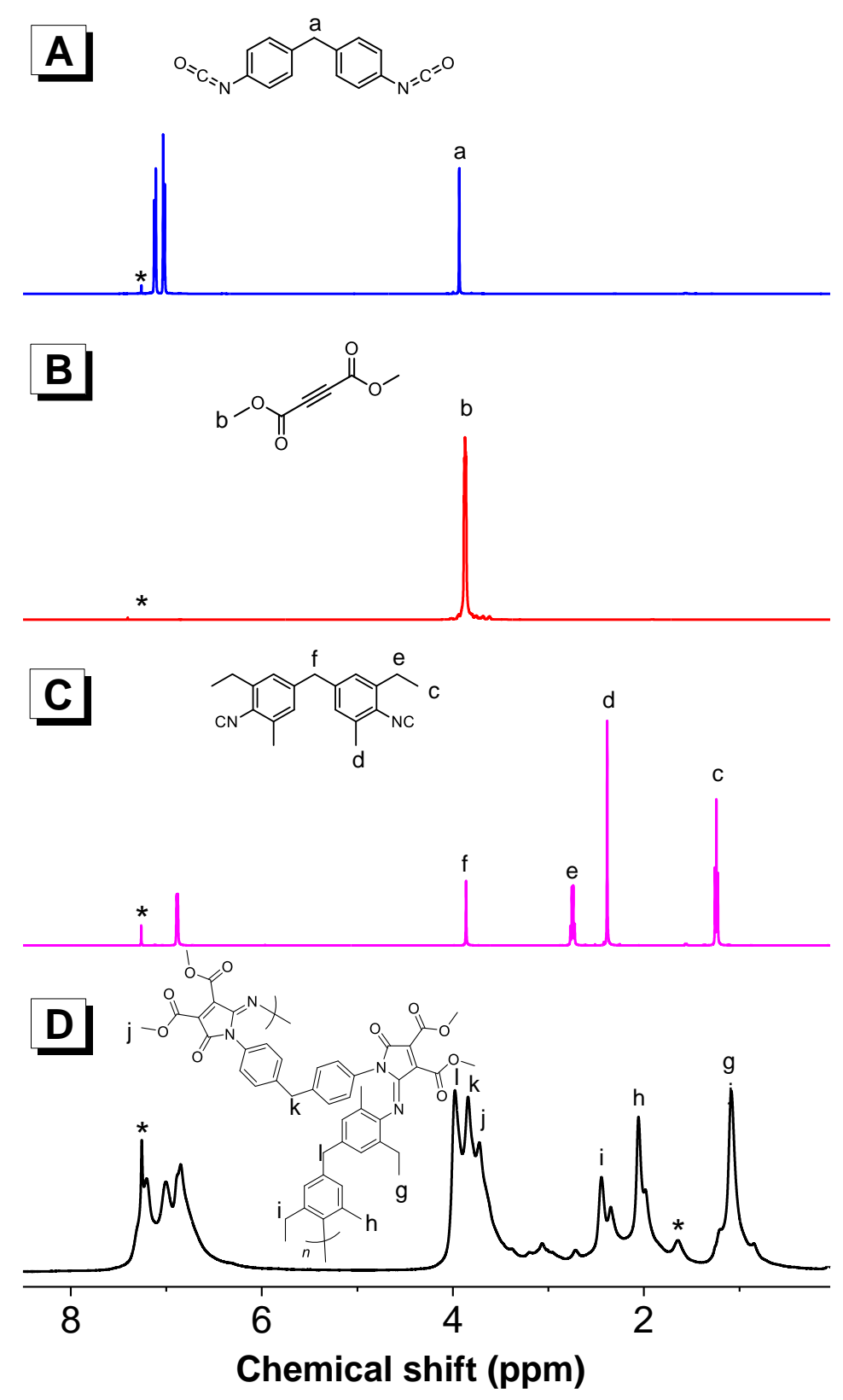

Figure S12. ${ }^{1} \mathrm{H}$ NMR spectra of $1 \mathbf{a}(\mathrm{A}), \mathbf{2 a}(\mathrm{B}), \mathbf{3 a}(\mathrm{C})$ and P1a2a3a (D) in $\mathrm{CDCl}_{3}$. The solvent peaks are marked with asterisks. 

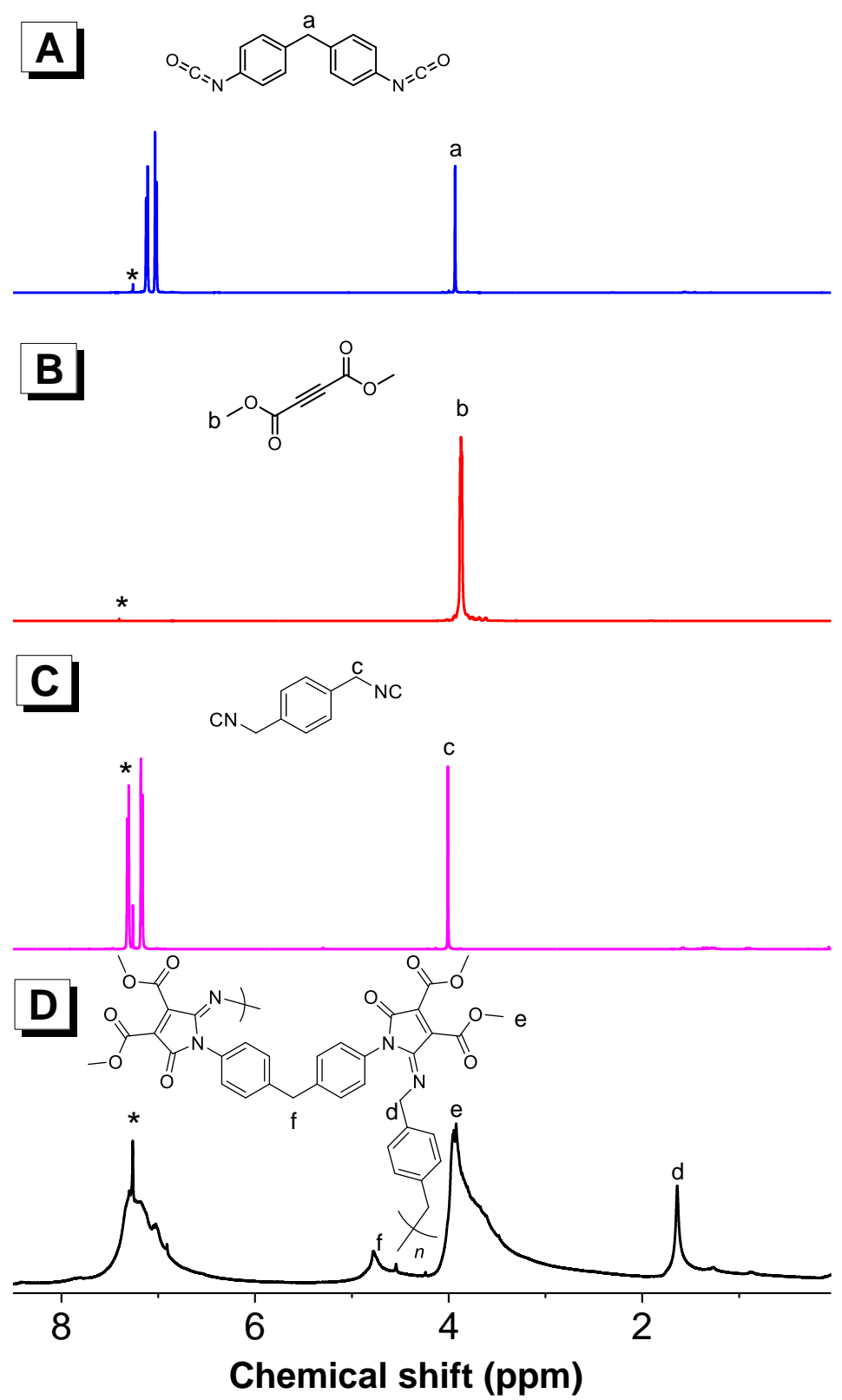

Figure S13. ${ }^{1} \mathrm{H}$ NMR spectra of $1 \mathbf{a}(\mathrm{A}), \mathbf{2 a}(\mathrm{B}), \mathbf{3 b}(\mathrm{C})$ and P1a2a3b (D) in $\mathrm{CDCl}_{3}$. The solvent peaks are marked with asterisks. 

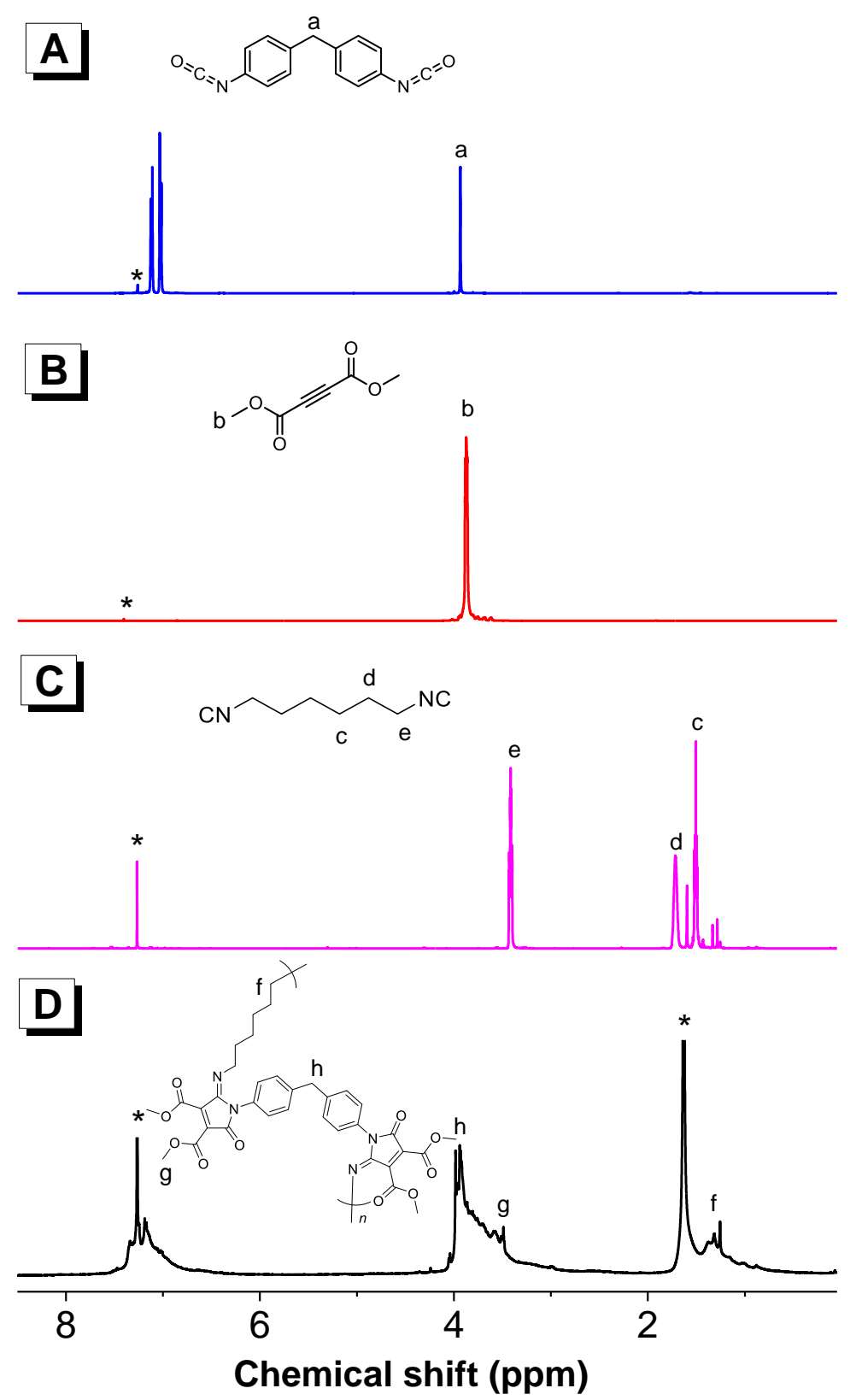

Figure S14. ${ }^{1} \mathrm{H}$ NMR spectra of $1 \mathbf{a}(\mathrm{A}), \mathbf{2 a}(\mathrm{B}), 3 \mathbf{c}(\mathrm{C})$ and P1a2a3c (D) in $\mathrm{CDCl}_{3}$. The solvent peaks are marked with asterisks. 

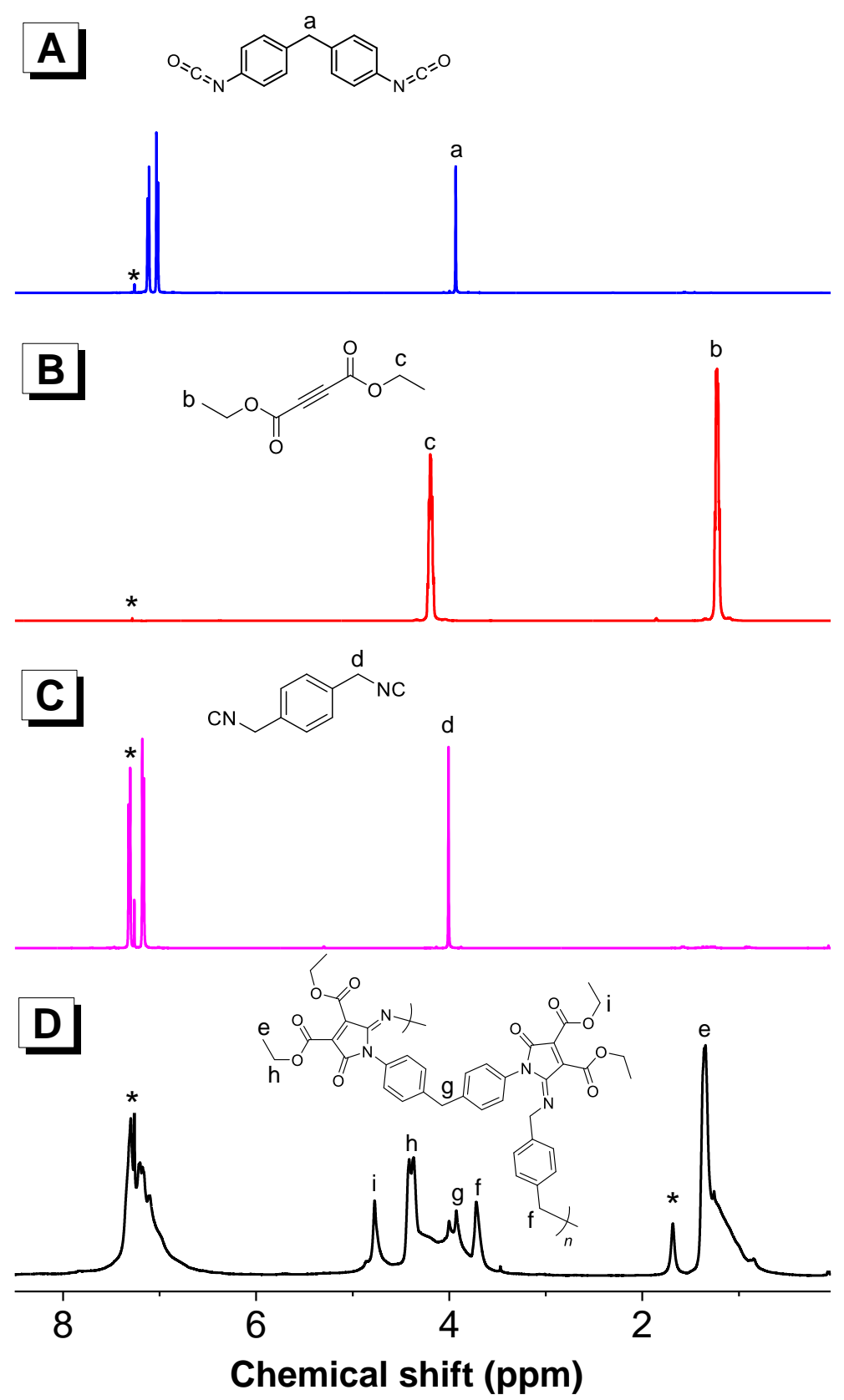

Figure S15. ${ }^{1} \mathrm{H}$ NMR spectra of $\mathbf{1 a}(\mathrm{A}), \mathbf{2 b}(\mathrm{B}), \mathbf{3 b}(\mathrm{C})$ and $\mathrm{P} 1 \mathbf{a} 2 \mathbf{b 3 b}(\mathrm{D})$ in $\mathrm{CDCl}_{3}$. The solvent peaks are marked with asterisks. 

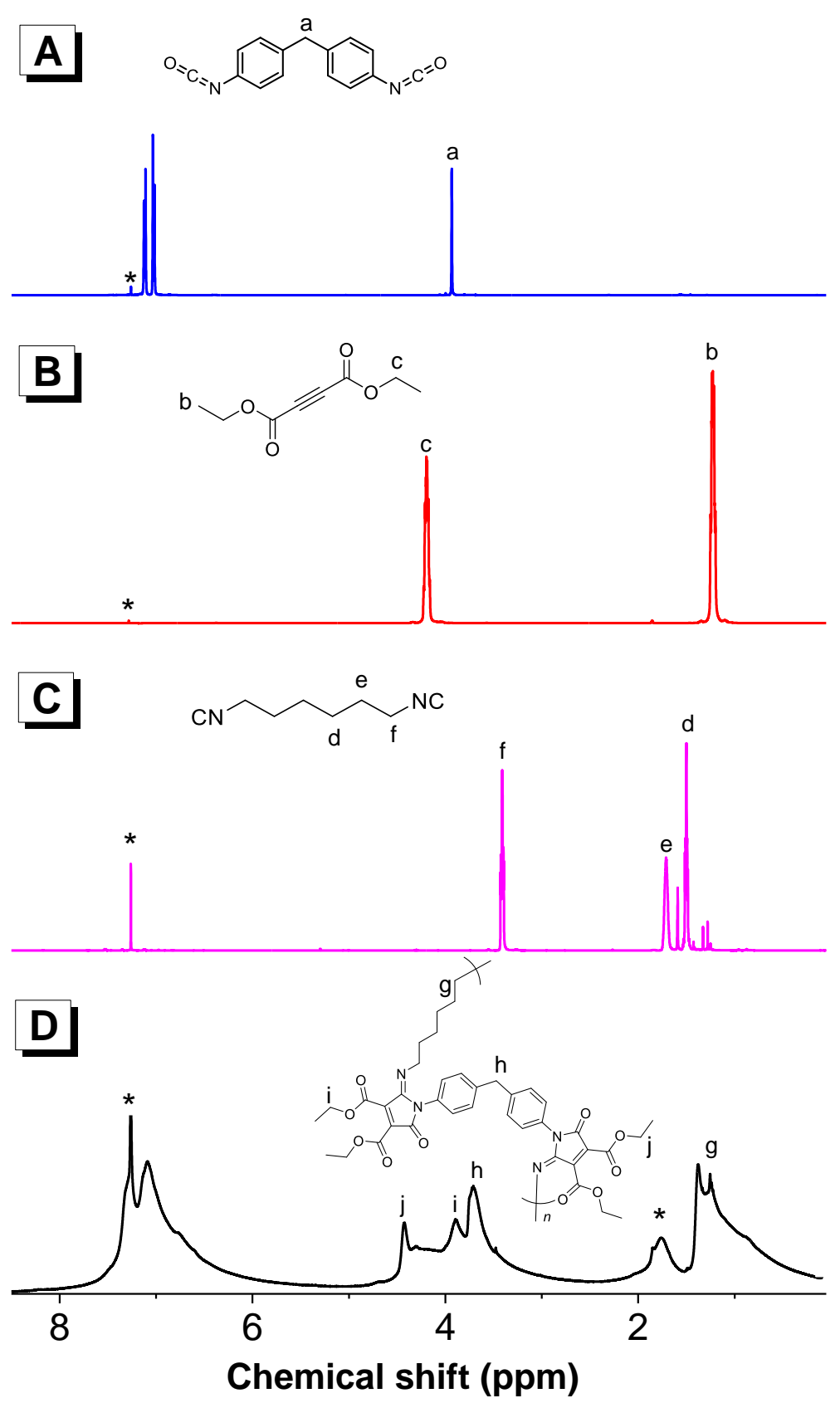

Figure S16. ${ }^{1} \mathrm{H}$ NMR spectra of $1 \mathbf{a}(\mathrm{A}), \mathbf{2 b}(\mathrm{B}), \mathbf{3 c}(\mathrm{C})$ and $\mathrm{P} 1 \mathbf{a} 2 \mathbf{b 3 c}(\mathrm{D})$ in $\mathrm{CDCl}_{3}$. The solvent peaks are marked with asterisks. 

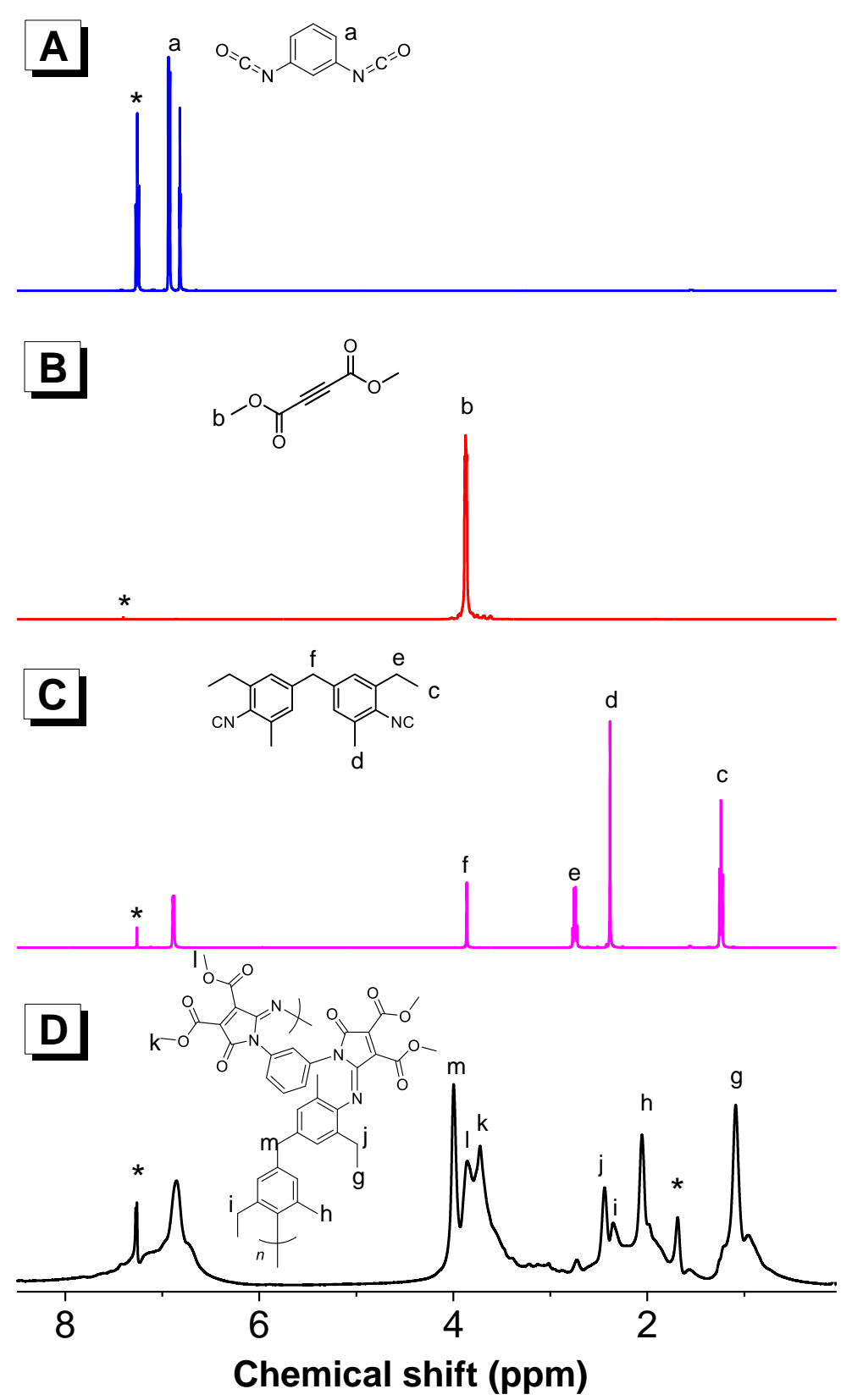

Figure S17. ${ }^{1} \mathrm{H}$ NMR spectra of $\mathbf{1 b}(\mathrm{A}), \mathbf{2 a}(\mathrm{B}), \mathbf{3 a}(\mathrm{C})$ and P1b2a3a (D) in $\mathrm{CDCl}_{3}$. The solvent peaks are marked with asterisks. 

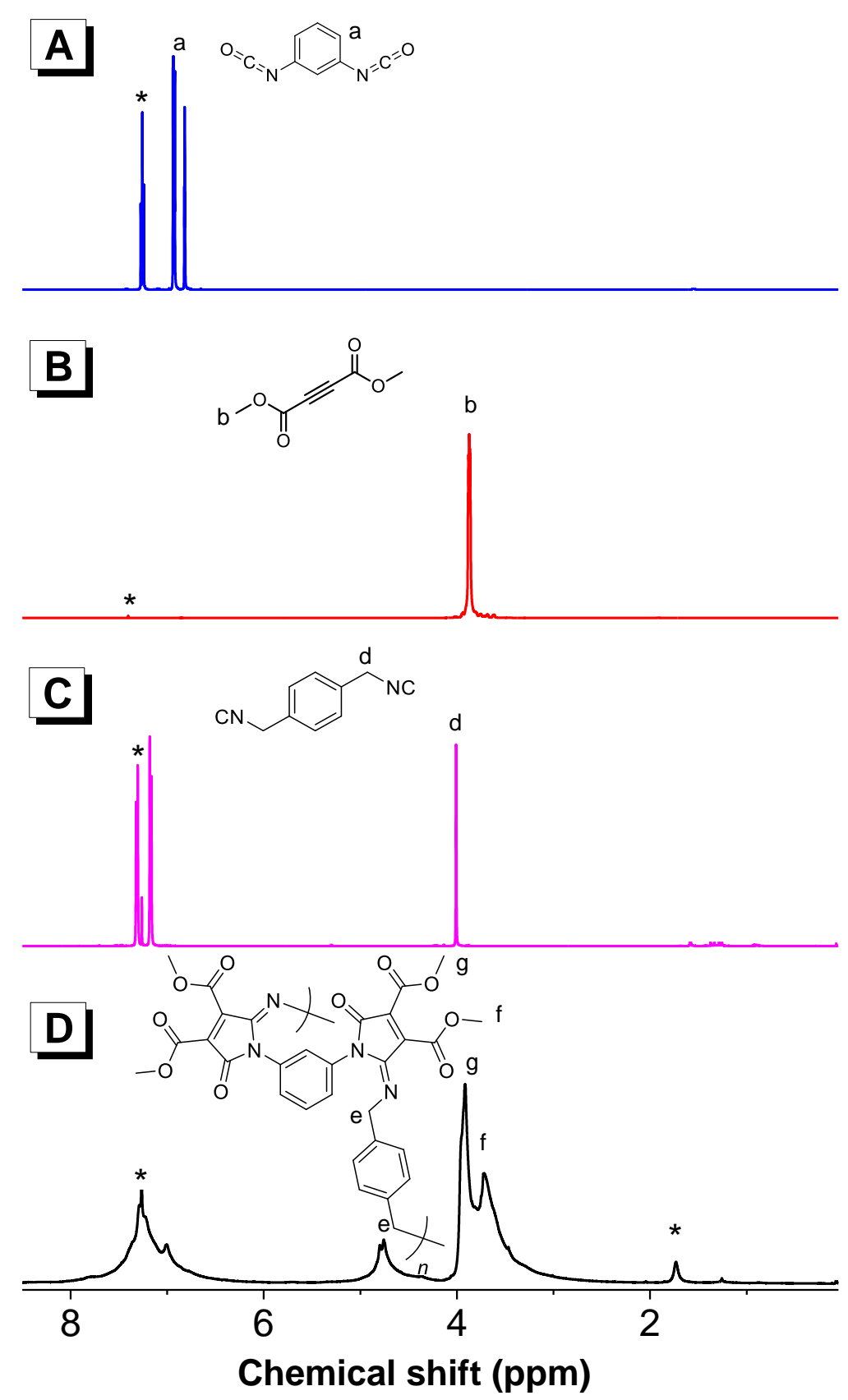

Figure S18. ${ }^{1} \mathrm{H}$ NMR spectra of $\mathbf{1 b}(\mathrm{A}), \mathbf{2 a}(\mathrm{B}), \mathbf{3 b}(\mathrm{C})$ and $\mathrm{P} \mathbf{1 b 2 a 3 b}$ (D) in $\mathrm{CDCl}_{3}$. The solvent peaks are marked with asterisks. 

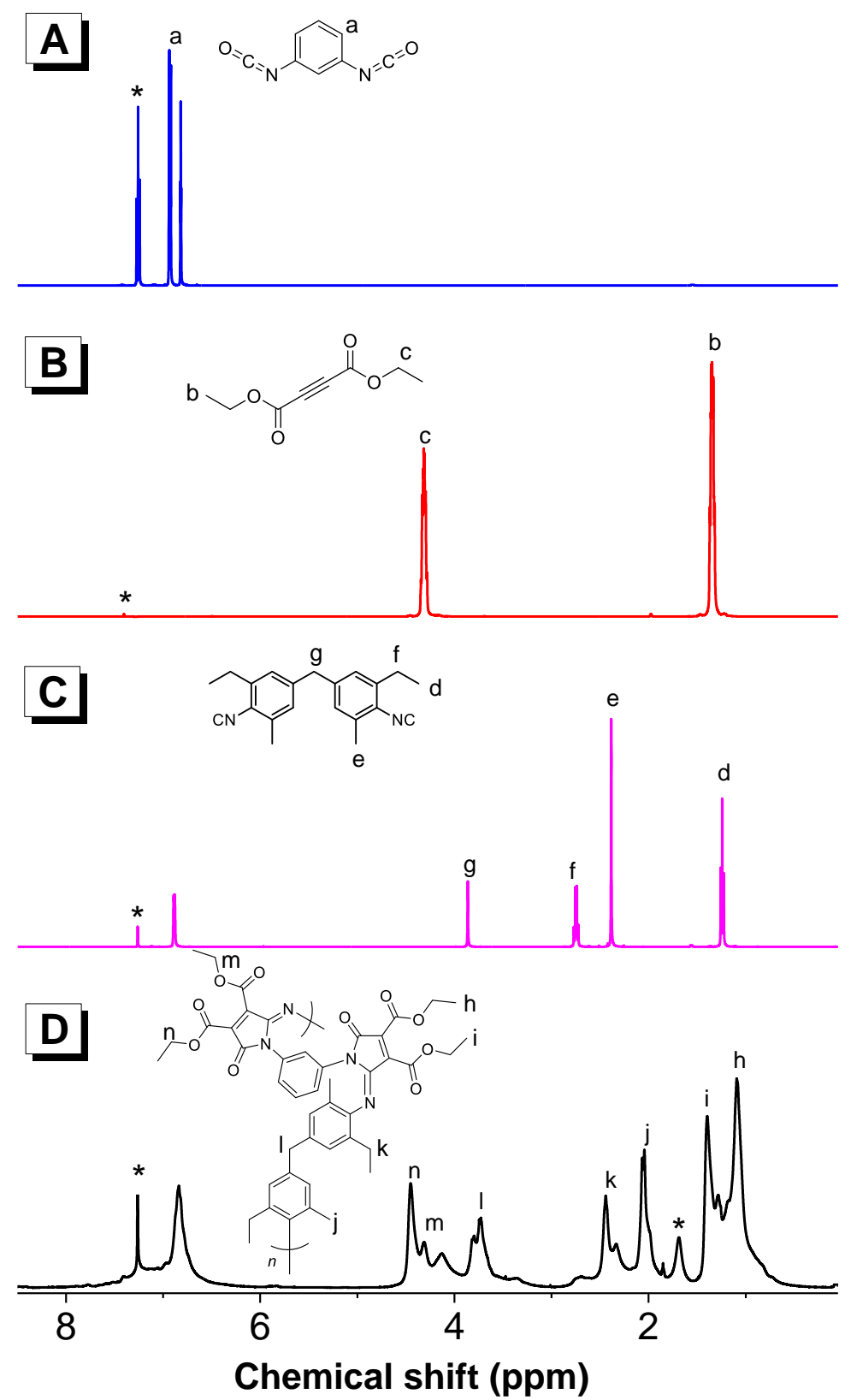

Figure S19. ${ }^{1} \mathrm{H}$ NMR spectra of $\mathbf{1 b}(\mathrm{A}), \mathbf{2 b}(\mathrm{B}), \mathbf{3 a}(\mathrm{C})$ and P1b2b3a (D) in $\mathrm{CDCl}_{3}$. The solvent peaks are marked with asterisks. 

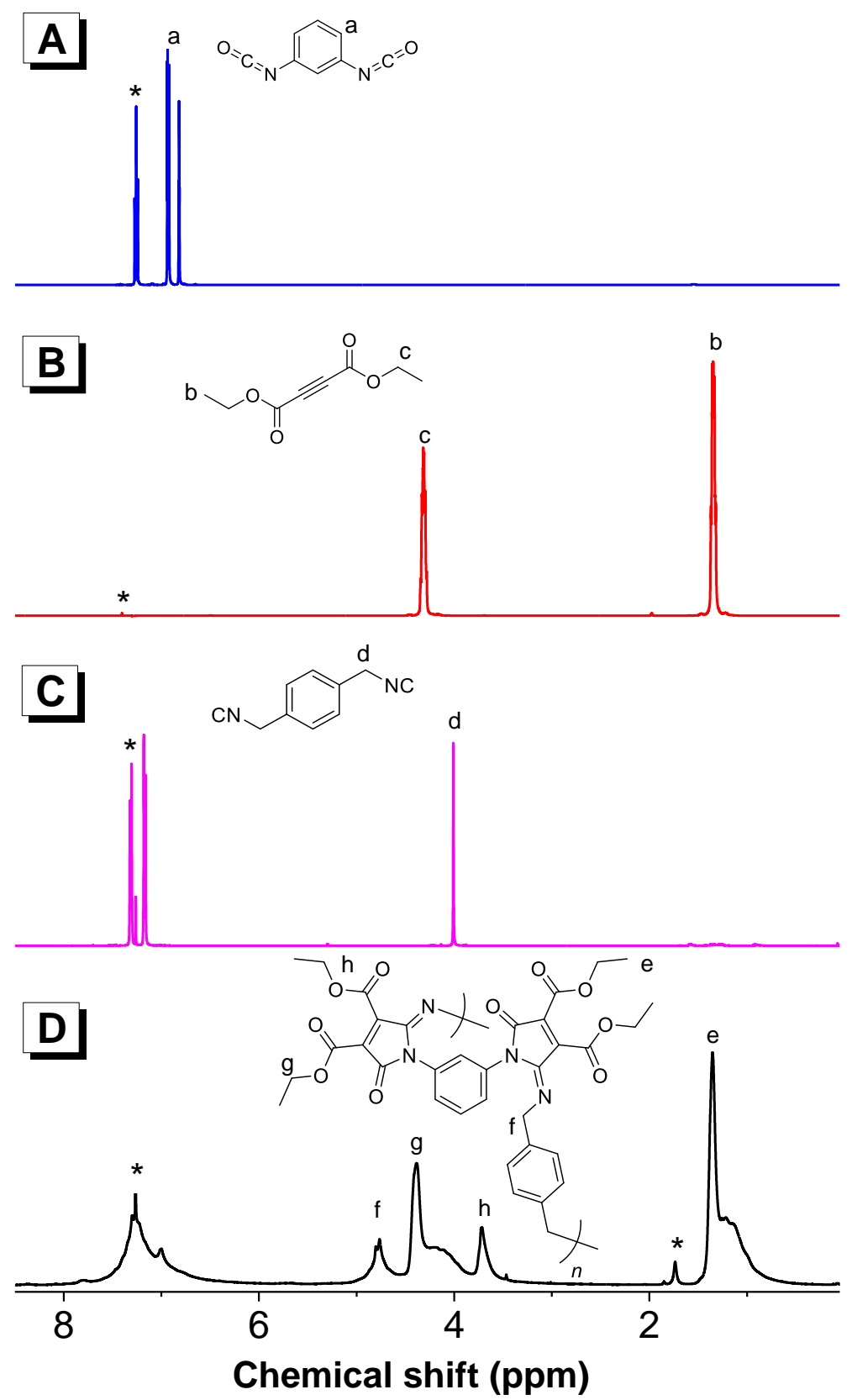

Figure S20. ${ }^{1} \mathrm{H}$ NMR spectra of $\mathbf{1 b}(\mathrm{A}), \mathbf{2 b}(\mathrm{B}), \mathbf{3 b}(\mathrm{C})$ and $\mathrm{P} \mathbf{1 b 2 b 3 b}(\mathrm{D})$ in $\mathrm{CDCl}_{3}$. The solvent peaks are marked with asterisks. 

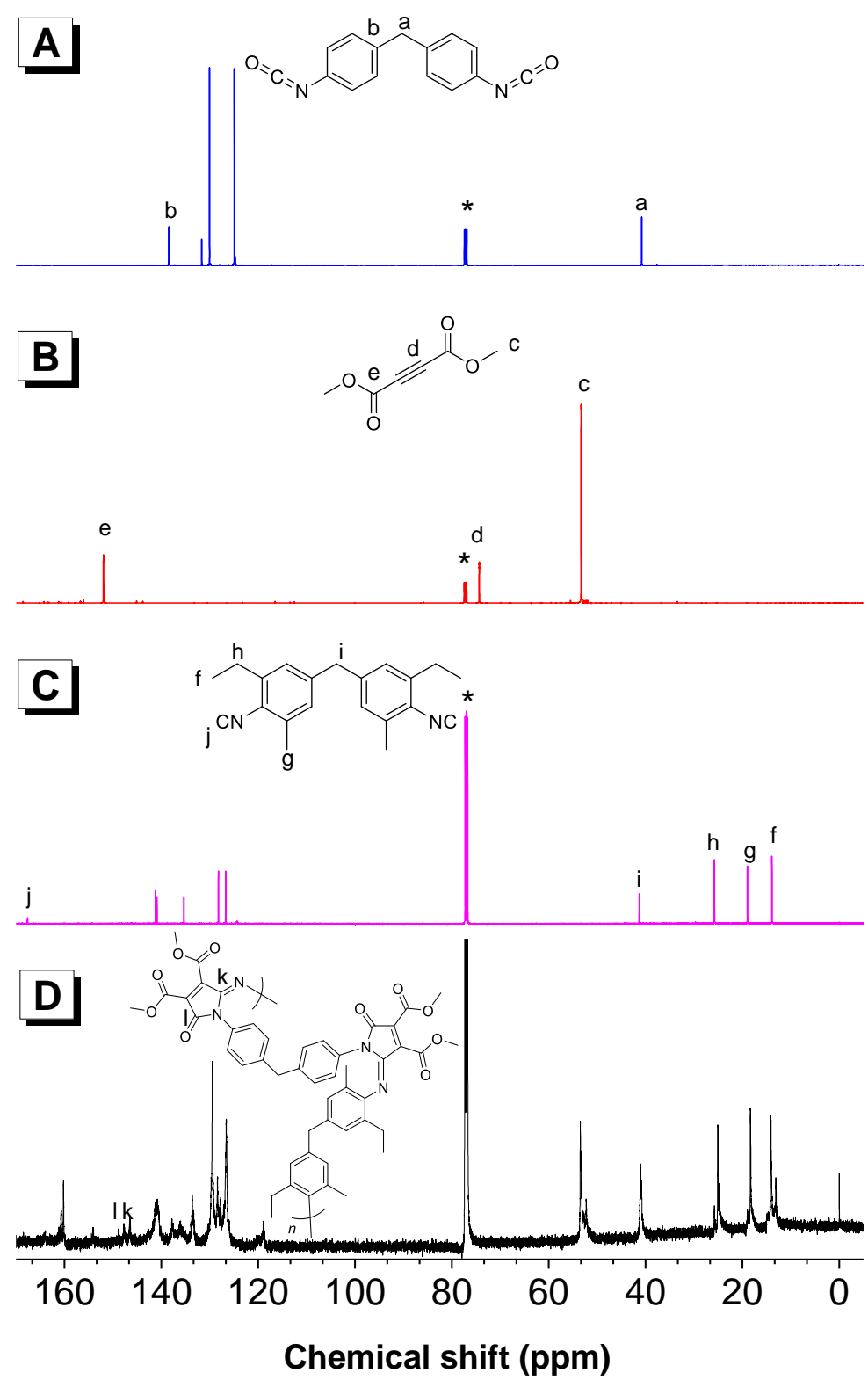

Figure S21. ${ }^{13} \mathrm{C}$ NMR spectra of $1 \mathbf{a}(\mathrm{A}), \mathbf{2 a}(\mathrm{B}), \mathbf{3 a}(\mathrm{C})$ and P1a2a3a (D) in $\mathrm{CDCl}_{3}$. The solvent peaks are marked with asterisks. 

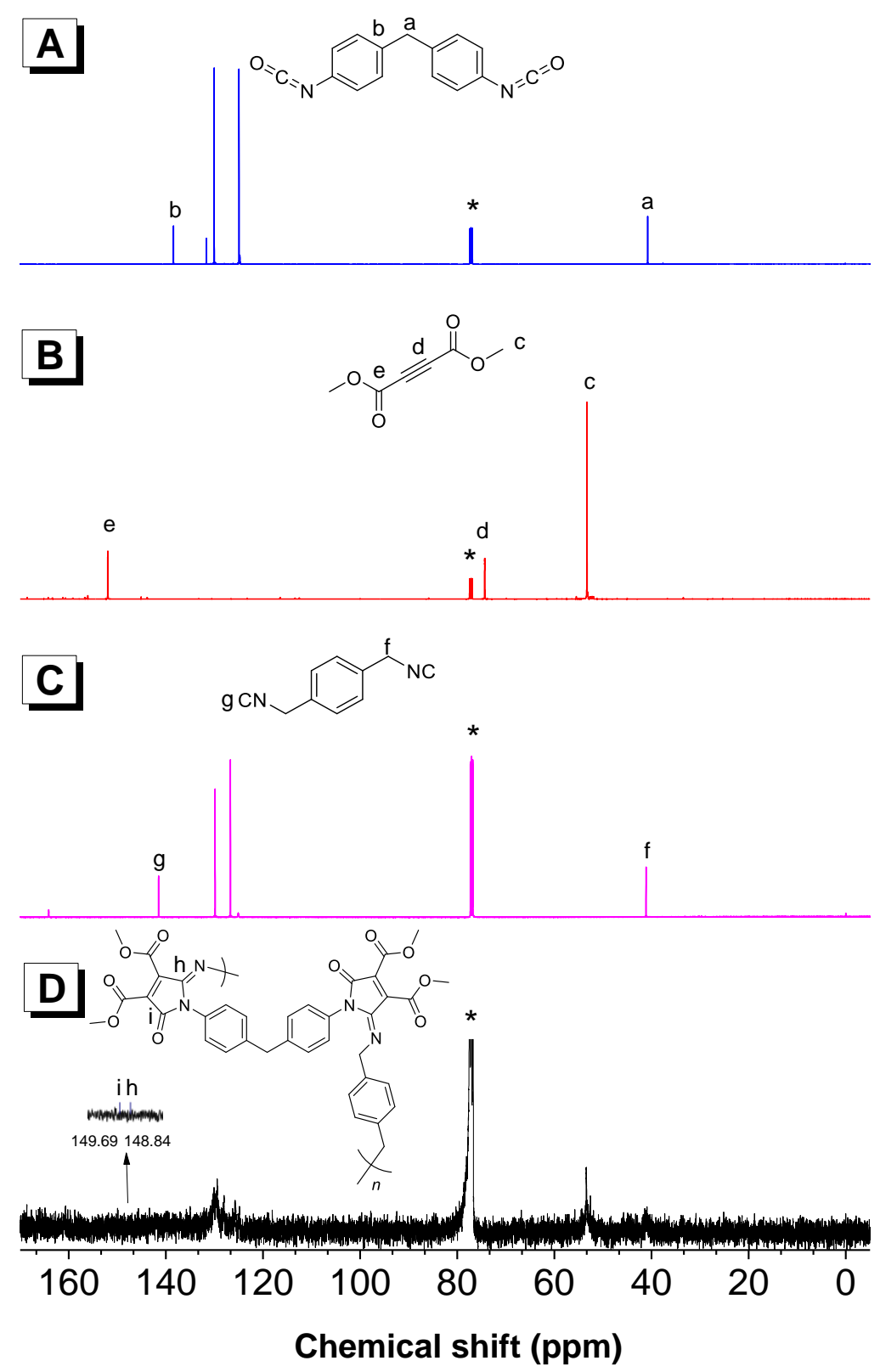

Figure S22. ${ }^{13} \mathrm{C}$ NMR spectra of $\mathbf{1 a}(\mathrm{A}), \mathbf{2 a}(\mathrm{B}), \mathbf{3 b}(\mathrm{C})$ and $\mathrm{P} 1 \mathbf{a} 2 \mathbf{a} 3 \mathbf{b}(\mathrm{D})$ in $\mathrm{CDCl}_{3}$. The solvent peaks are marked with asterisks. 

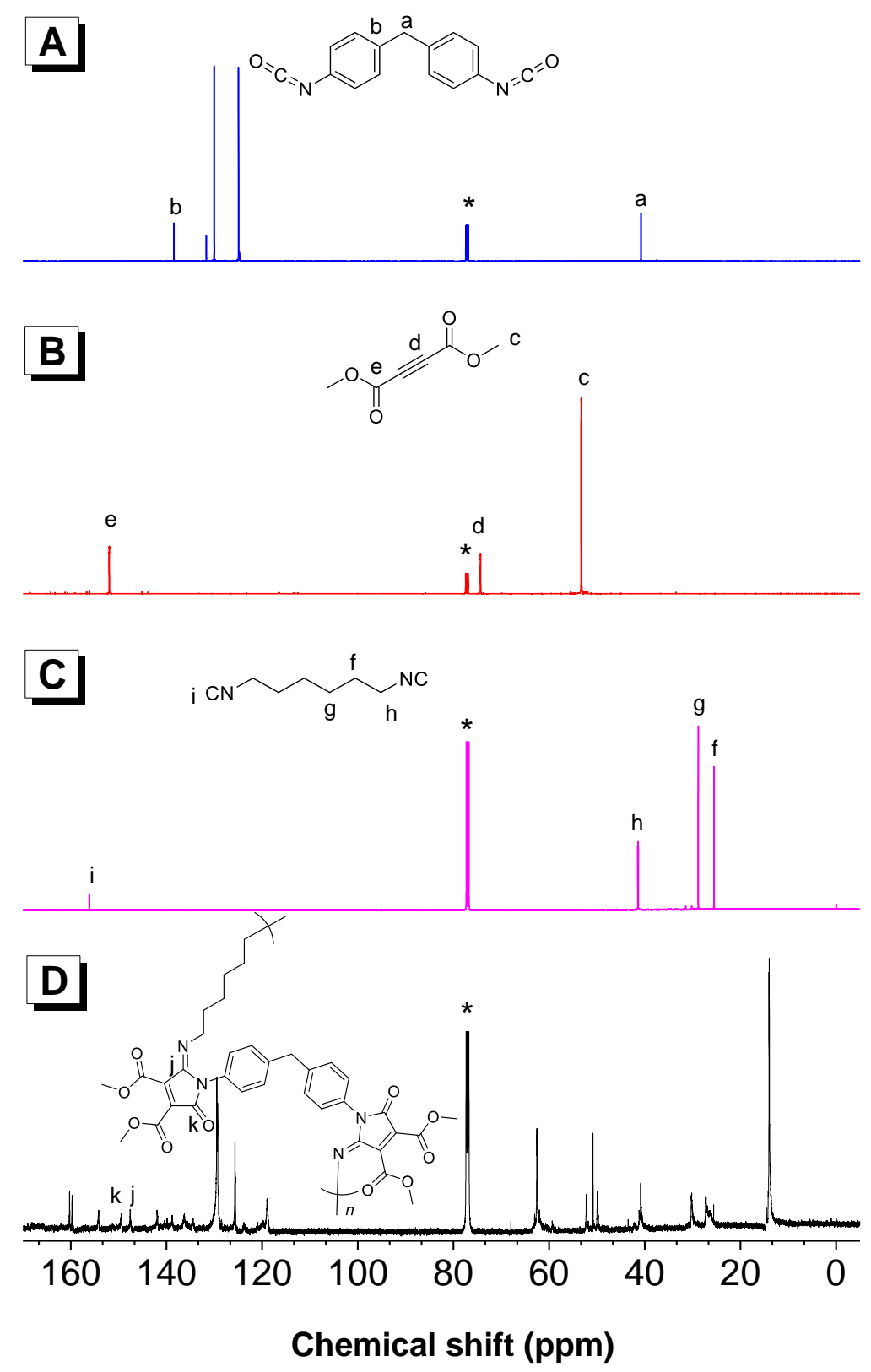

Figure S23. ${ }^{13} \mathrm{C}$ NMR spectra of $1 \mathbf{a}(\mathrm{A}), \mathbf{2 a}(\mathrm{B}), \mathbf{3 c}(\mathrm{C})$ and P1a2a3c (D) in $\mathrm{CDCl}_{3}$. The solvent peaks are marked with asterisks. 

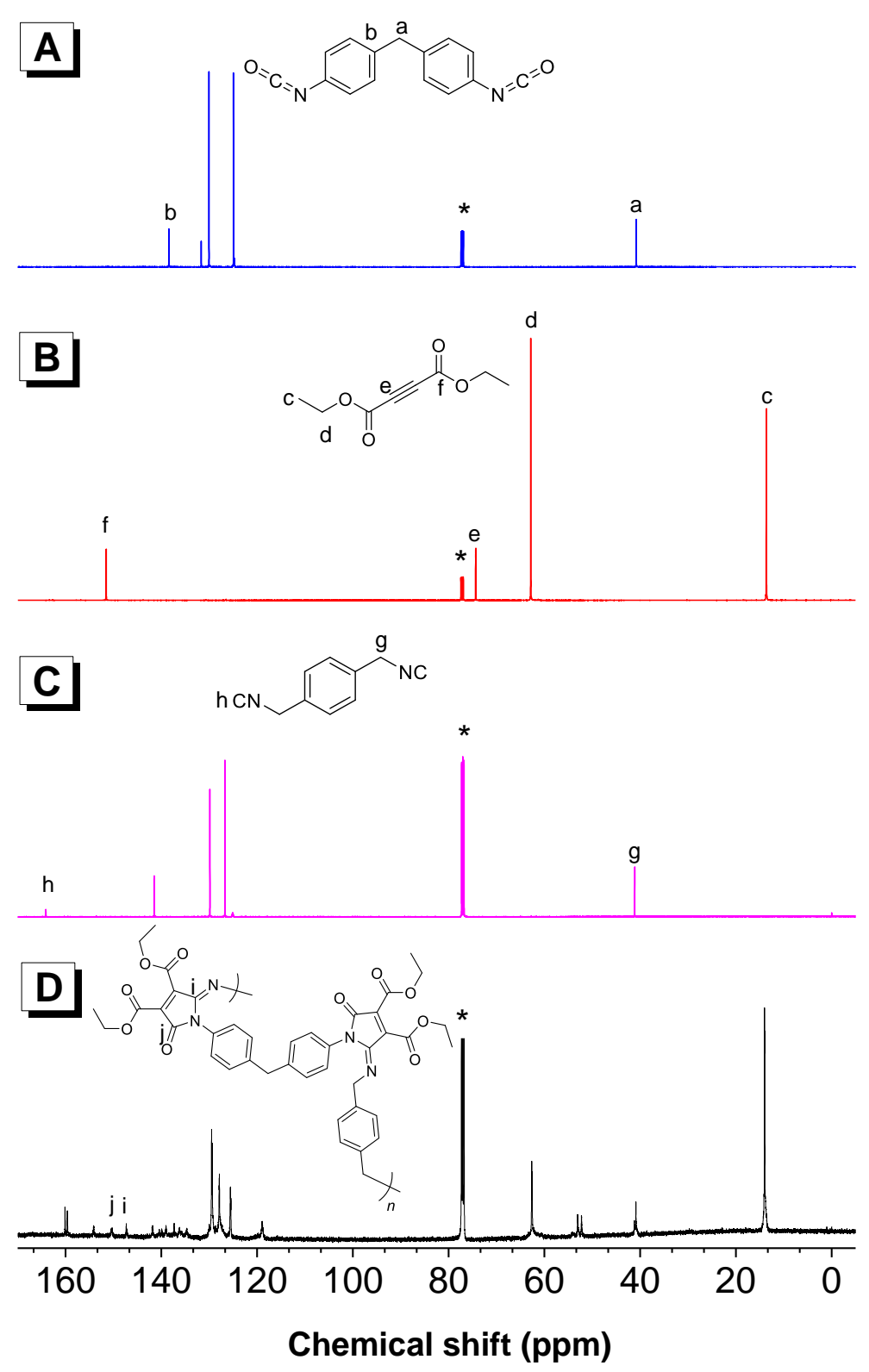

Figure S24. ${ }^{13} \mathrm{C}$ NMR spectra of $1 \mathbf{a}(\mathrm{A}), \mathbf{2 b}(\mathrm{B}), \mathbf{3 b}(\mathrm{C})$ and $\mathrm{P} \mathbf{1 a 2 b 3 b}(\mathrm{D})$ in $\mathrm{CDCl}_{3}$. The solvent peaks are marked with asterisks. 

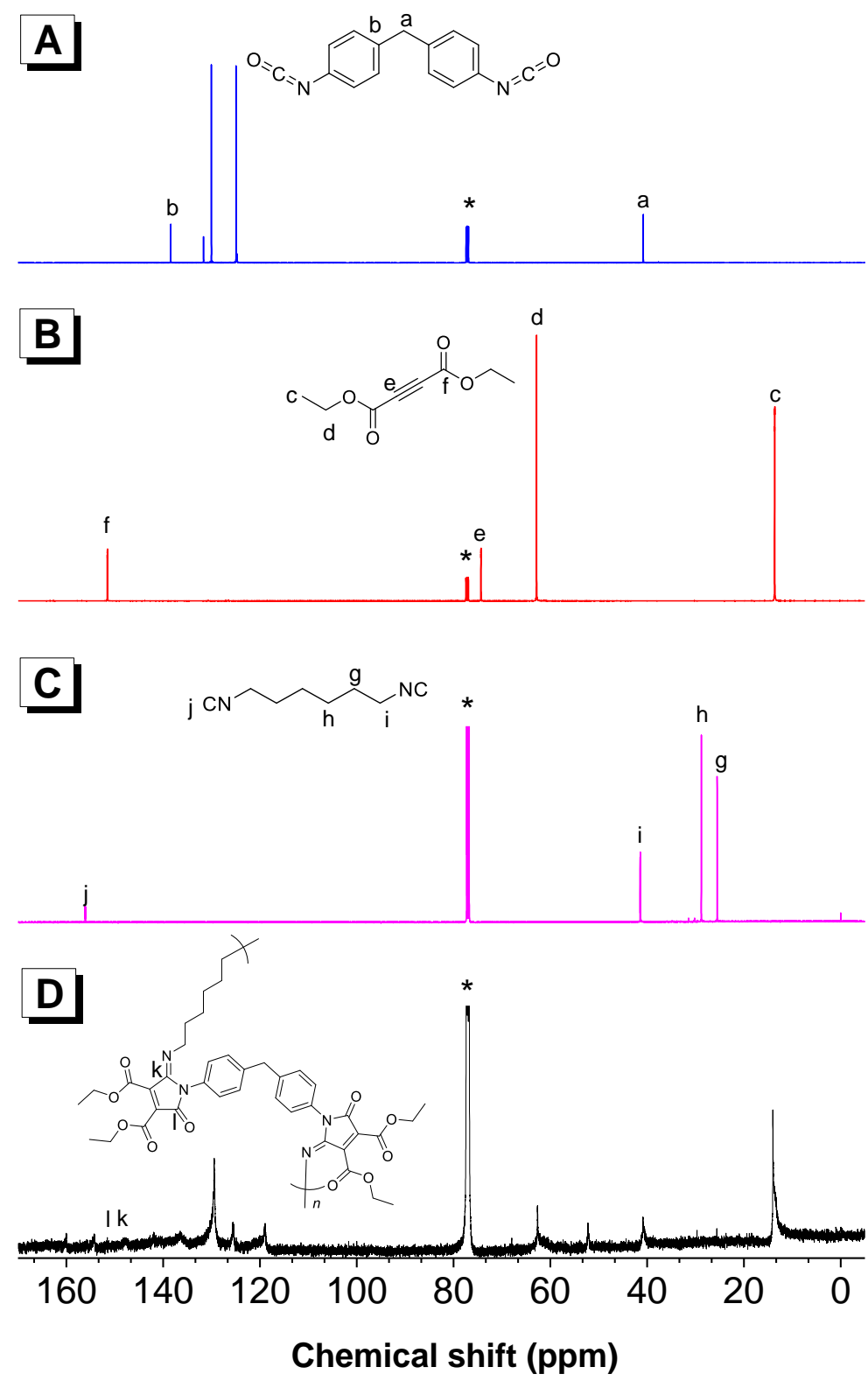

Figure S25. ${ }^{13} \mathrm{C}$ NMR spectra of $1 \mathbf{a}(\mathrm{A}), \mathbf{2 b}(\mathrm{B}), \mathbf{3 c}(\mathrm{C})$ and $\mathrm{P} 1 \mathbf{a 2 b 3 c}(\mathrm{D})$ in $\mathrm{CDCl}_{3}$. The solvent peaks are marked with asterisks. 

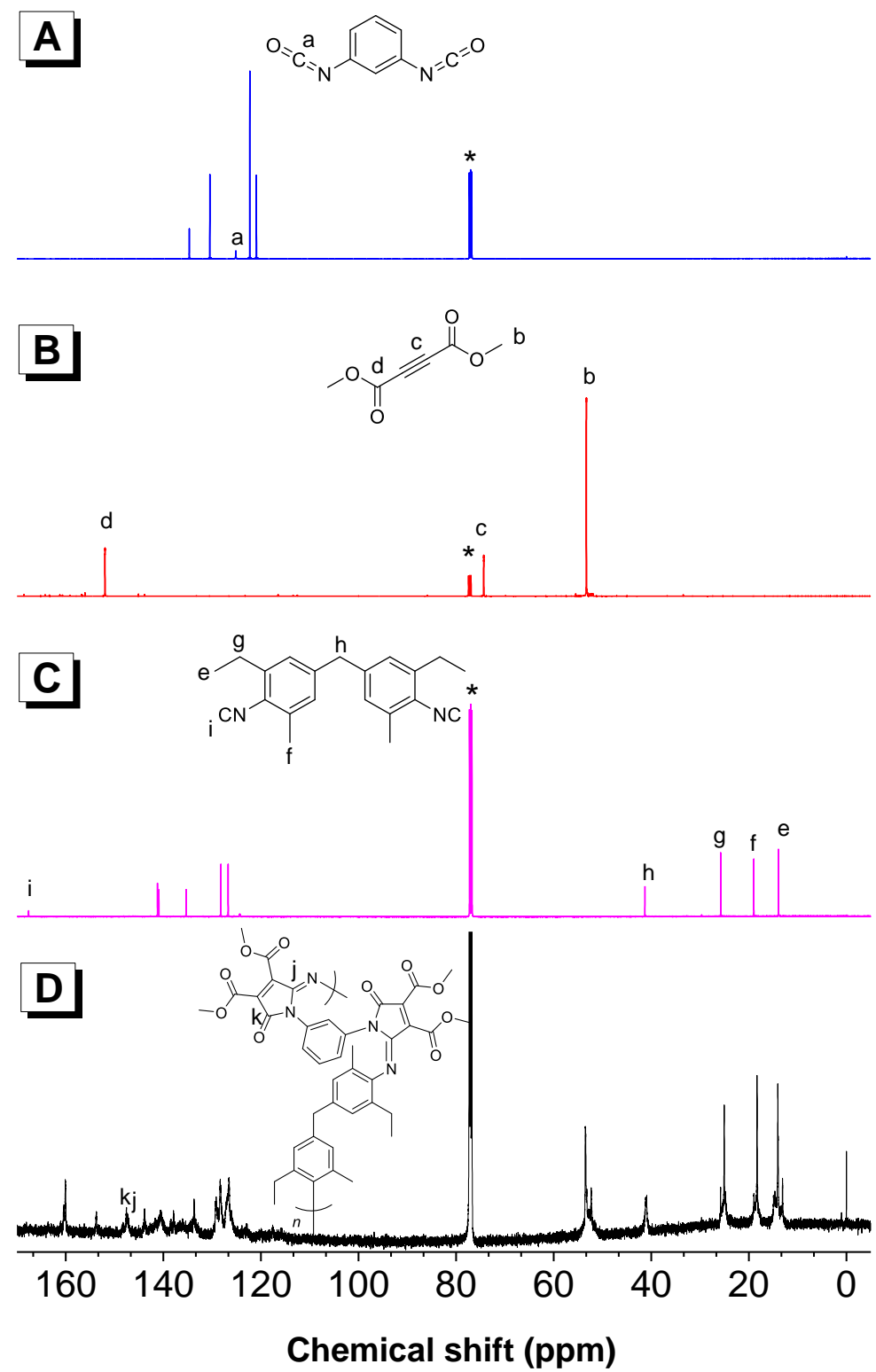

Figure S26. ${ }^{13} \mathrm{C}$ NMR spectra of $\mathbf{1 b}(\mathrm{A}), \mathbf{2 a}(\mathrm{B}), \mathbf{3 a}(\mathrm{C})$ and P1b2a3a (D) in $\mathrm{CDCl}_{3}$. The solvent peaks are marked with asterisks. 

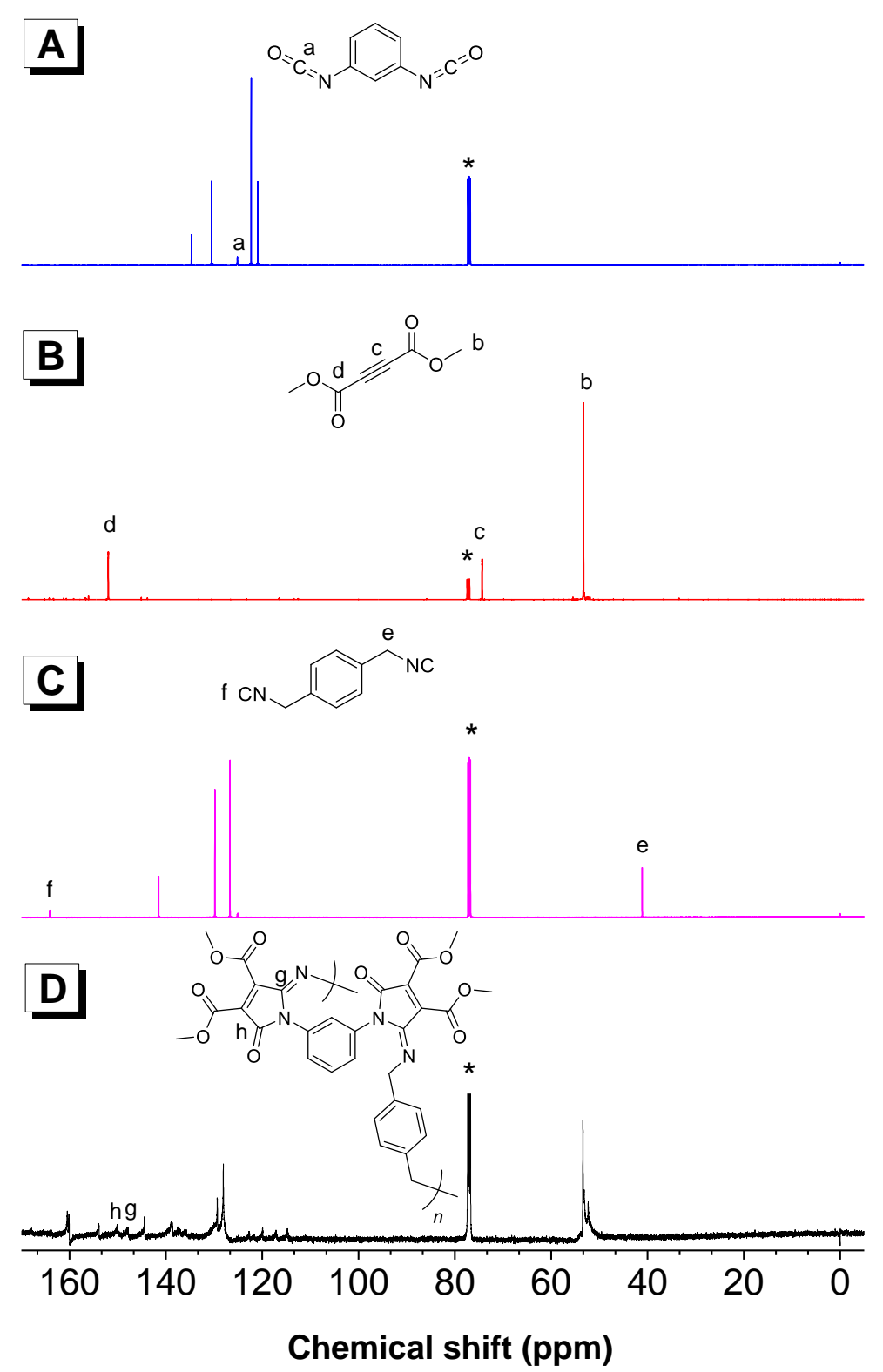

Figure S27. ${ }^{13} \mathrm{C}$ NMR spectra of $\mathbf{1 b}(\mathrm{A}), \mathbf{2 a}(\mathrm{B}), \mathbf{3 b}(\mathrm{C})$ and P1b2a3b (D) in $\mathrm{CDCl}_{3}$. The solvent peaks are marked with asterisks. 

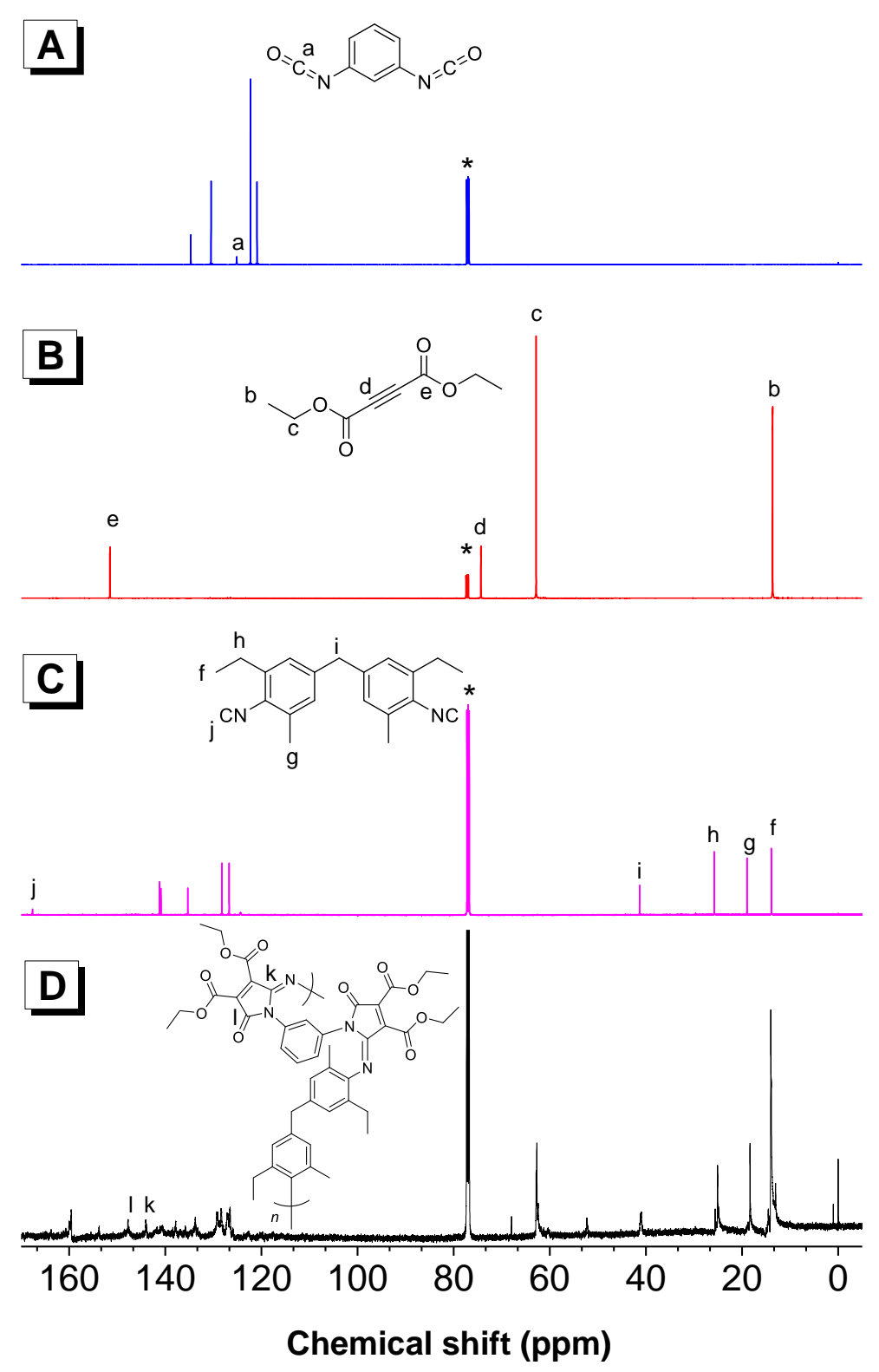

Figure S28. ${ }^{13} \mathrm{C}$ NMR spectra of $\mathbf{1 b}(\mathrm{A}), \mathbf{2 b}(\mathrm{B}), \mathbf{3 a}(\mathrm{C})$ and $\mathrm{P} 1 \mathbf{b 2 b 3 a}(\mathrm{D})$ in $\mathrm{CDCl}_{3}$. The solvent peaks are marked with asterisks. 

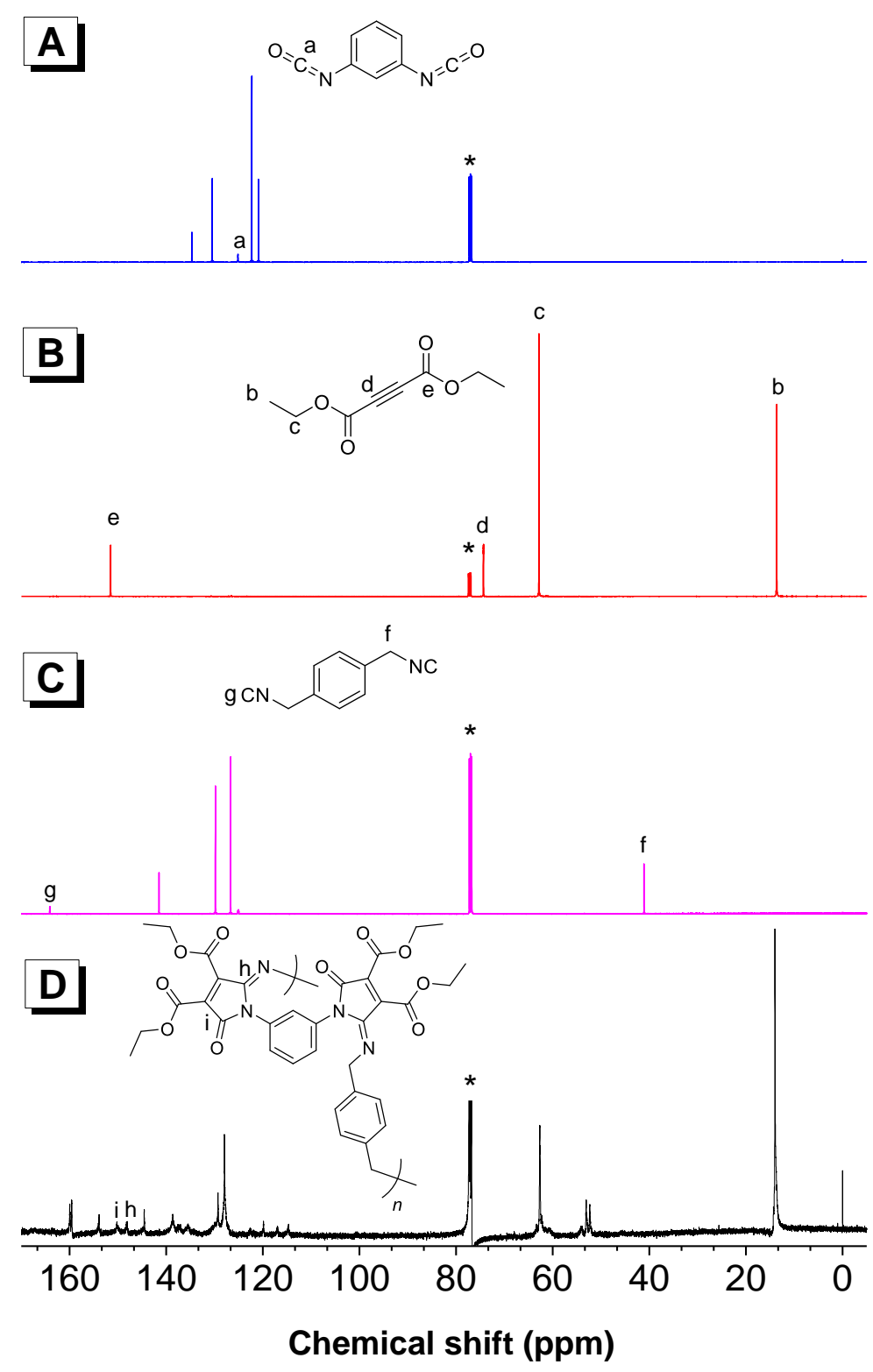

Figure S29. ${ }^{13} \mathrm{C}$ NMR spectra of $\mathbf{1 b}(\mathrm{A}), \mathbf{2 b}(\mathrm{B}), \mathbf{3 b}(\mathrm{C})$ and $\mathrm{P} \mathbf{1 b 2 b 3 b}(\mathrm{D})$ in $\mathrm{CDCl}_{3}$. The solvent peaks are marked with asterisks. 

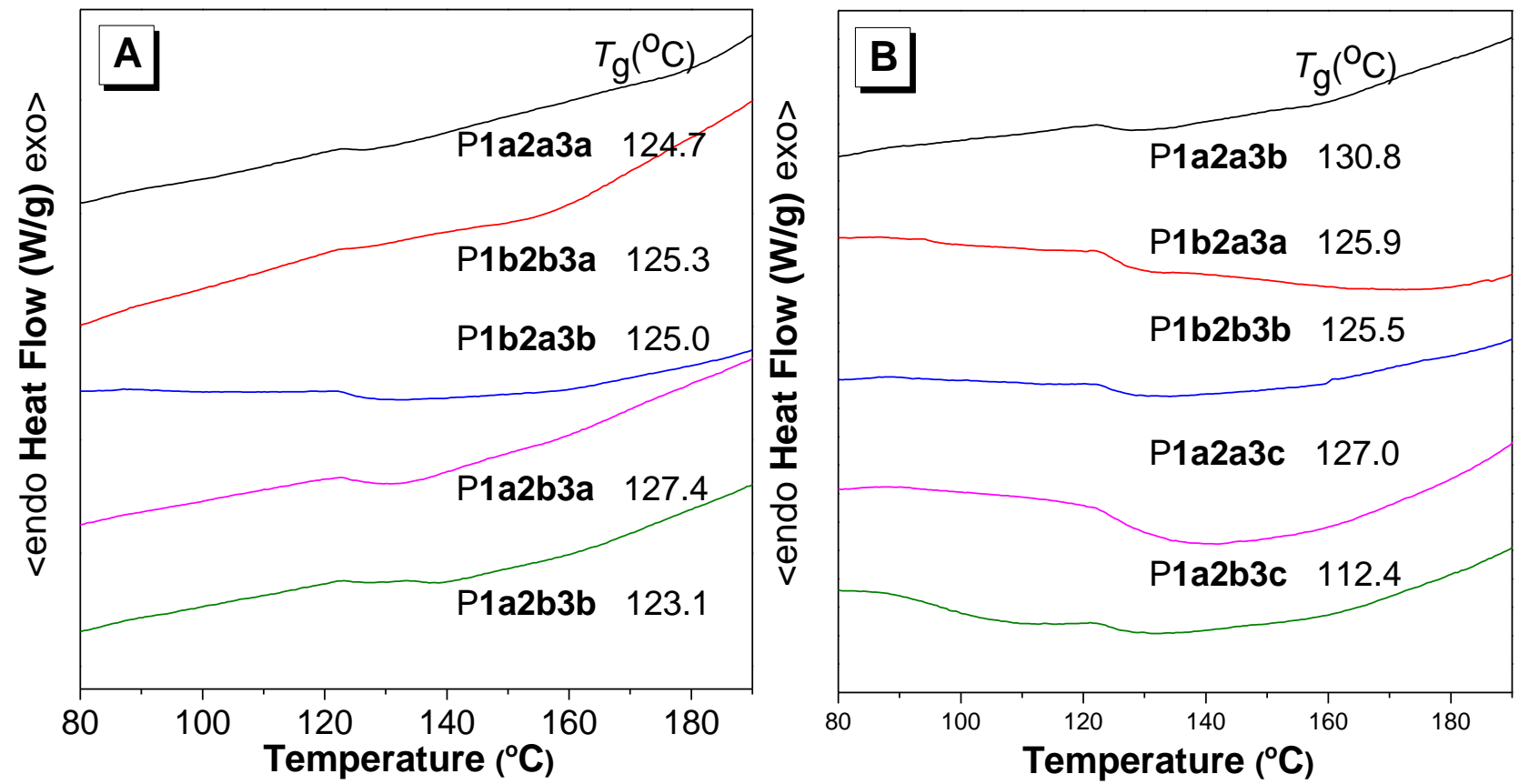

Figure S30. (A) Differential scanning calorimetry (DSC) analysis of P1a2a3a-P1a2b3b. (B) DSC analysis of P1a2a3b-P1a2b3c.

Table S1. The Effect of Acidic Conditions on P1a2a3a. ${ }^{a}$

\begin{tabular}{ccccc}
\hline entry & $\mathrm{pH}$ & Recovery $(\%)$ & $M_{\mathrm{w}}{ }^{b}$ & $\oplus^{b}$ \\
\hline 1 & 1 & 23 & 16700 & 2.16 \\
2 & 2 & 95 & 25000 & 2.71 \\
3 & 3 & 100 & 25000 & 2.70 \\
4 & 4 & 100 & 25000 & 2.65 \\
5 & 5 & 100 & 25000 & 2.73 \\
6 & 6 & 100 & 25000 & 2.70
\end{tabular}

${ }^{a}$ Stirring in $\mathrm{HCl} / \mathrm{THF}$ for $5 \mathrm{~h}^{b}$ Estimated by gel permeation chromatography (GPC) in tetrahydrofuran (THF) on the basis of a polystyrene (PS) calibration. $M_{\mathrm{w}}=$ weight-average molecular weight; polydispersity index $(\bigoplus)=M_{\mathrm{w}} / M_{\mathrm{n}}, M_{\mathrm{n}}=$ number-average molecular weight. 

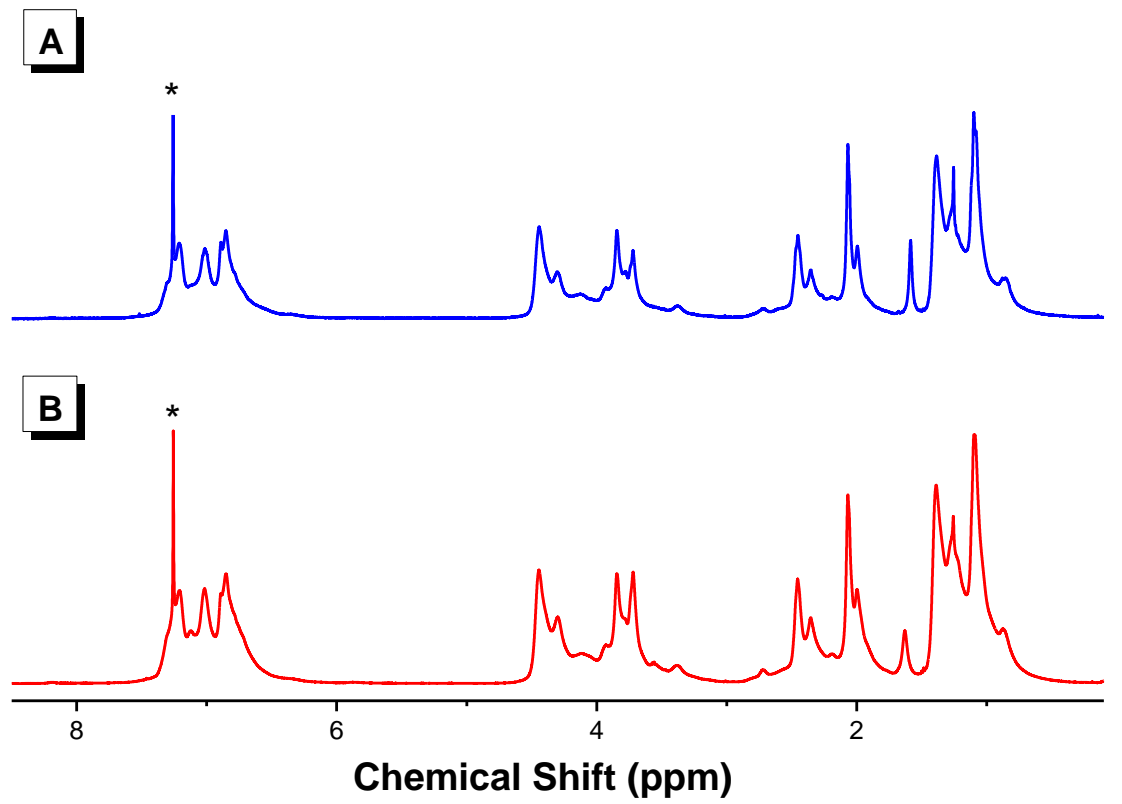

Figure S31. ${ }^{1} \mathrm{H}$ NMR spectra of P1a2b3a before (A) and after (B) stirring in $\mathrm{THF} / \mathrm{HCl}$ with $\mathrm{pH}=3$. The solvent peaks are marked with asterisks.

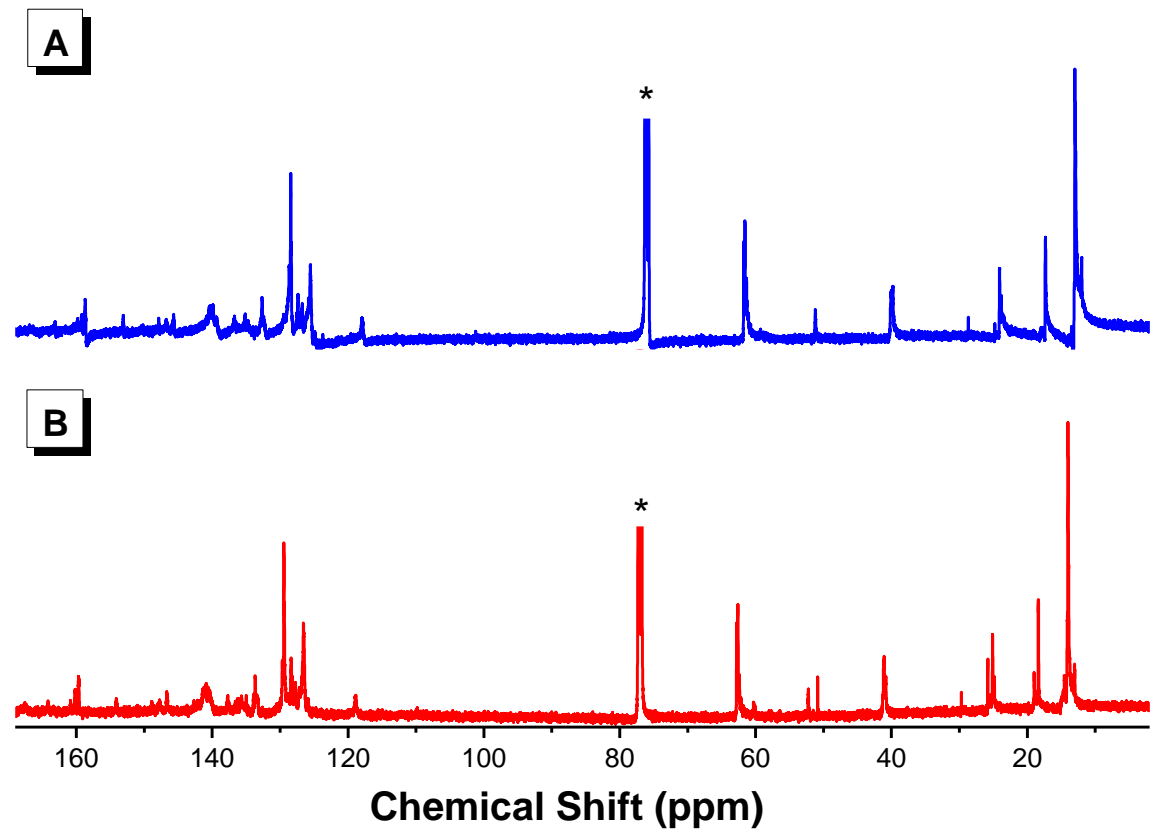

Figure S32. ${ }^{13} \mathrm{C}$ NMR spectra of P1a2b3a before (A) and after (B) stirring in $\mathrm{THF} / \mathrm{HCl}$ with $\mathrm{pH}=3$. The solvent peaks are marked with asterisks. 

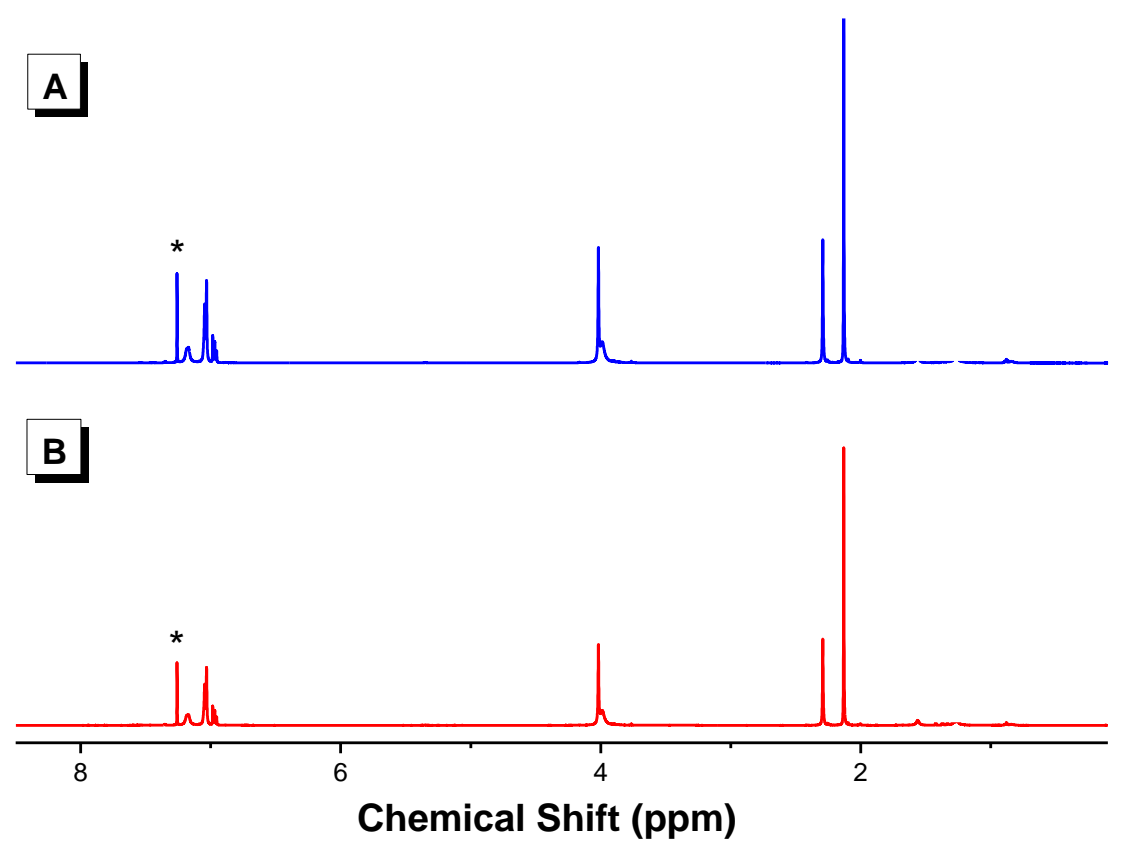

Figure S33. ${ }^{1} \mathrm{H}$ NMR spectra of model compound 4 before (A) and after (B) stirring in $\mathrm{THF} / \mathrm{HCl}$ with $\mathrm{pH}=3$. The solvent peaks are marked with asterisks.
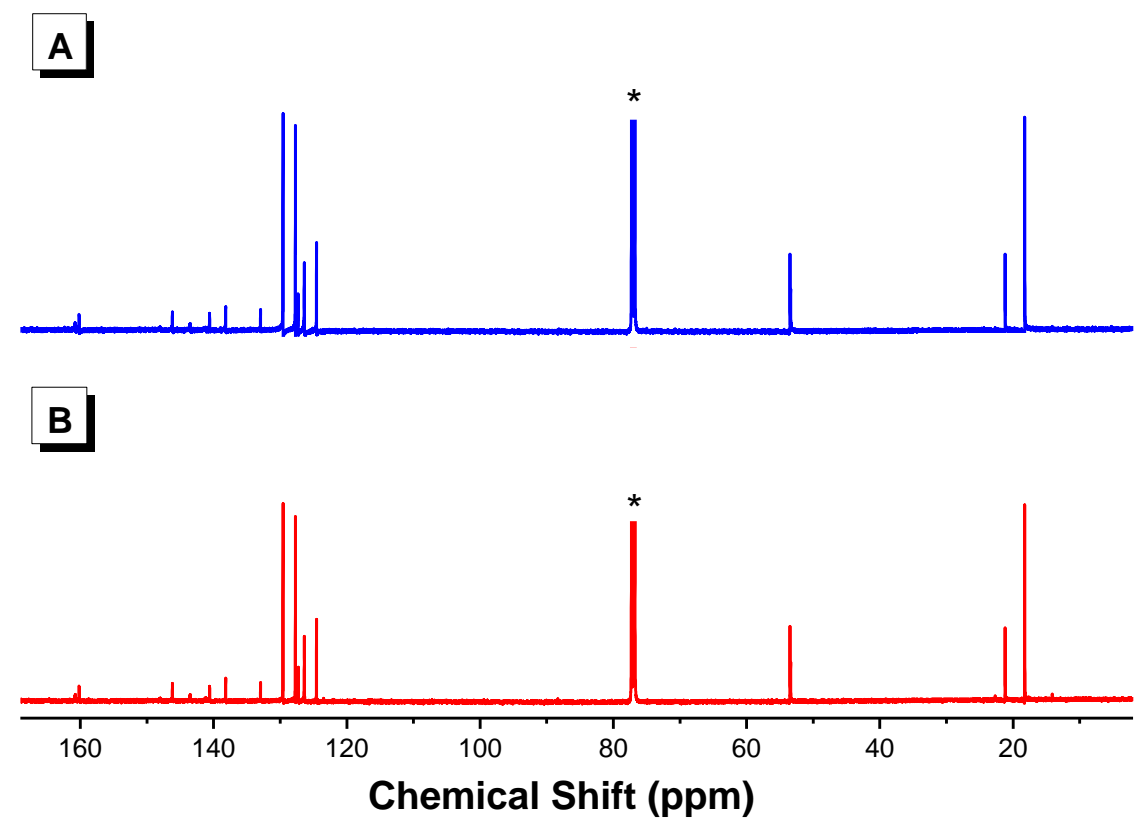

Figure S34. ${ }^{13} \mathrm{C}$ NMR spectra of model compound 4 before (A) and after (B) stirring in $\mathrm{THF} / \mathrm{HCl}$ with $\mathrm{pH}=3$. The solvent peaks are marked with asterisks. 
Table S2. Refractive indices $\left(n_{\mathrm{D}}\right)$, Abbé numbers $\left(V_{\mathrm{D}}\right)$, modified Abbé numbers $\left(\nu_{\mathrm{D}}^{\prime}\right)$, optical dispersions $\left(D\right.$ and $\left.D^{\prime}\right)$ and thickness of thin films of polymers P1a2a3a-P1b2b3b.

\begin{tabular}{lcccccc}
\hline polymer & $n_{\mathrm{D}}{ }^{a}$ & $v_{\mathrm{D}}{ }^{b}$ & $D^{c}$ & $v^{\prime}{ }^{d}$ & $D^{\prime e}$ & thickness (nm) \\
\hline P1a2a3a & 1.638 & 32.0 & 0.0313 & 123.4 & 0.0081 & 60.13 \\
P1a2a3b & 1.683 & 36.1 & 0.0277 & 165.8 & 0.0060 & 201.81 \\
P1a2a3c & 1.649 & 20.5 & 0.0489 & 303.0 & 0.0033 & 39.36 \\
P1a2b3a & 1.695 & 6.7 & 0.1490 & 223.3 & 0.0045 & 44.14 \\
P1a2b3b & 1.710 & 29.8 & 0.0336 & 137.4 & 0.0073 & 60.54 \\
P1a2b3c & 1.614 & 30.8 & 0.0325 & 116.8 & 0.0086 & 207.01 \\
P1b2a3a & 1.635 & 39.8 & 0.0252 & 154.5 & 0.0065 & 204.81 \\
P1b2a3b & 1.645 & 20.3 & 0.0492 & 49.8 & 0.0201 & 198.60 \\
P1b2b3a & 1.634 & 17.3 & 0.0579 & 44.9 & 0.0223 & 48.33 \\
P1b2b3b & 1.646 & 32.4 & 0.0309 & 156.3 & 0.0064 & 27.87
\end{tabular}

${ }^{a}$ Data of polymers at $632.8 \mathrm{~nm} .{ }^{b} v_{\mathrm{D}}=\left(n_{589.3-1}\right) /\left(n_{486.1}-n_{656.3}\right) .{ }^{c} D=1 / v_{\mathrm{D}} .{ }^{d} v_{\mathrm{D}}^{\prime}=\left(n_{1319-1}\right) /\left(n_{1060}-n_{1550}\right)$.

${ }^{e} D^{\prime}=1 / v^{\prime}$.

Table S3. Refractive indices $\left(n_{\mathrm{D}}\right)$ of commercial polymers

\begin{tabular}{cc}
\hline Commercial polymer & $n_{\mathrm{D}}{ }^{a}$ \\
\hline Polyvinyl chloride & 1.541 \\
Polyetherimide & 1.489 \\
Polyvinyl alcohol & 1.623 \\
Polydimethylsiloxane & 1.429 \\
Polyvinylpyrrolidone & 1.526 \\
Polylactic acid & 1.453 \\
Cellulose & 1.469 \\
Polycarbonate & 1.587 \\
Polystyrene & 1.58 \\
Poly(methyl methacrylate $)$ & 1.489
\end{tabular}

${ }^{a}$ Data of commercial polymers at $632.8 \mathrm{~nm}$ taken from refractive index database. 


\section{References}

(1) Tian T.; Hu R.; Tang B. Z. One-Pot Multicomponent Tandem Reactions and Polymerizations for Step-Economic Synthesis of Structure-Controlled Pyrimidine Derivatives and Poly(pyrimidine)s. $J$. Am. Chem. Soc., 2018, 19, 6156-6163.

(2) Khatereh, K.; Malek, T. M.; Nourallah, H.; Sayyed M. H.; Seyed, S. S. One-Pot, Three Component Reactions between Isocyanides and Dialkyl Acetylenedicarboxylates in the Presence of Phenyl Isocyanate: Synthesis of Dialkyl 2-(alkyl/arylimino)-2,5-dihydro-5-oxo-1-phenyl-1H-pyrrole-3,4dicarboxylate. Arkivoc 2011, 22-28. 